\title{
LOS INICIOS DEL IMPUESTO SUCESORIO EN EL DERECHO ROMANO
}

\author{
Maria Eugénia Ortuño Pérez \\ Doutora em Direito. Profesora Titular de Derecho Romano \\ da Universidad de Barcelona (España).
}

RESUMEN: Teniendo en cuenta el contexto político-jurídico de finales de la República romana, se trata de determinar el origen y los motivos que llevaron al poder público de esta época a crear y aplicar, sin conseguirlo, una tasa que gravara las herencias.

PALABRAS CLAVE: Poder político; Inflación; Gastos militares; Impuestos indirectos; Egipto.

\section{Os inícios do imposto sucessório no Direito Romano}

RESUMO: Tendo em conta o contexto politico-legal do fim da República Romana, trata-se de determinar a origem e os motivos que levaram o poder público deste período a criar e aplicar, sem sucesso, um imposto sobre a herança.

PALAVRAS-CHAVE: Poder político; Inflação; Despesas militares; Impostos indiretos; Egito.

\section{Early beginnings of the inheritance tax in the Roman Law}

ABSTRACT: Referred to the political and legal context of the late Roman Republic, the aim of this research is to determine the origins and reasons which act the public power to the creation and further failed application of a fee taxing inheritance.

KEYWORDS: Political context; Inflation; Military outlay; Indirect duties; Egypt.

\section{INTRODUCCIÓN}

La propuesta (año 5 d.C.), y la posterior aplicación (año 13 d.C.), de la Lex Iulia de Vicesima Hereditatium por parte de Augusto, con la que estableció una tasa del 5\% sobre las herencias y los legados otorgados a ciudadanos romanos ${ }^{1}$, no fue más que el final de un largo recorrido que se había iniciado mucho tiempo antes. Se había planteado por César, al que siguieron sus sucesores, los triunviros Octaviano, Antonio y Lépido, consiguiendo idénticos resultados. En ninguno de los dos casos se logró su imposición, aunque por motivos distintos. En el primero, el dictador no pudo llevar a cabo su proyecto antes de ser asesinado. En el segundo, aunque se logró plantear su imposición, no llegó a aplicarse por la fuerte oposición popular.

El desarrollo de estos acontecimientos nos ha llevado a plantearnos cuáles fueron los motivos o las circunstancias que pudieron conducir al poder político romano de finales del S. I a.C., en plena crisis de la República, a plantear la creación e intentar la aplicación de este impuesto indirecto que debería gravar las transmisiones patrimoniales por causa de muerte. Y cuál pudo ser la fuente de su configuración.

Así, pues, nos hemos propuesto tratar de dejar al descubierto el origen y los motivos que llevaron a intentar la creación de esta tasa. Y para ello hemos llevado a cabo un estudio del

1 Gai 3,125; Coll. XVI, 9,3. Dion Casio 55,25. Cfr.: ROTONDI, G., Leges publicae populi romani. (Hildesheim- Zürich - New York, 1990), p. 457. 
contexto político-jurídico en el que se desarrollaron los acontecimientos, sirviéndonos, sobretodo, de las noticias históricas basadas en fuentes de esta misma naturaleza².

\section{EL SEGUNDO TRIUNVIRATO Y LA APLICACIÓN DEL MEMORANDUM DE JULIO CÉSAR: El ACTA CAESARIANA}

Con el asesinato de Julio César ${ }^{3}$ finalizó también el breve período de paz conseguido con su dictadura ${ }^{4}$ tras el primer triunvirato ${ }^{5}$. Con su muerte, se interrumpió, también, la reorganización política y administrativa del Estado que estaba llevando a cabo paralelamente a la asunción de poderes personales ${ }^{6}$, a la vez que vaciaba de contenido las competencias de algunos órganos constitucionales republicanos ${ }^{7}$. Se ha dicho que "organizó una verdadera y propia reestructuración de las relaciones de poder en la ciudad"8. Su particular visión política, aparentemente basada en ideales democráticos, se centraba, de hecho, en un gobierno absolutista de corte helenístico, que él mismo pretendía ejercer mediante la dictadura político-militar ${ }^{9}$, de carácter constituyente

2 FERNÁNDEZ DE BUJÁN, A., "Perspectivas de estudio en temática de Derecho Administrativo romano surgidas a tenor del pensamiento y de la obra de Giambattista Impallomeni", en INDEX 26 (1998), pp. 464 ss. ID., "Hacia un tratado de Derecho Administrativo y Fiscal Romano", en SDHI 77 (2011), pp. 441-478 = RGDR 24 (2010).

3 El asesinato tuvo lugar el 17 de marzo del año 44 a.C. Cfr.: WARDE FOWLER, W., Jules César et la fondation du régime impérial romain. Trad. francesa (París, 1958), pp. 250 ss., entre otros.

4 DE MARTINO, F., Storia della costituzione romana. Vol. IV. Parte prima. (Napoli, 1962), pp. 43 ss. BECERRA OLIVA, G., La República romana: organización política, luchas sociales y guerras civiles. (Buenos Aires, 1944), pp. 195 ss. ARBIZU, J. M., Res Publica Opresa. Política popular en la crisis de la República (133-44 a.C.). (Madrid, 2000), pp. 305 ss. KAMM, A., Iulius Caesar (London-New York, 2006), pp. 101 ss. El período de paz se vio temporalmente interrumpido porque César tuvo que luchar contra los pompeyanos en España. Esta contienda se inició por el hijo de Pompeyo y por Labieno y finalizó en el año 45aC. con la victoria de César que, siendo ya cónsul, logró convertirse en dictador. Cfr.: PARIBENI, R., L'età di Cesare e di Augusto. (Bologna, 1950), pp. 196 y 201, respectivamente. Desde otra perspectiva, $c f r$., también, CASCIONE, C., Studi di Dirito Pubblico Romano. (Napoli, 2010), p. 21 y nota 49. MASI DORIA, C., Spretum Imperium. (Napoli, 2000), pp. 207 ss.

5 PAIS, E., "L'aspirazione di Cesare al trono e l'opposizione tribunicia durante gli anni 45-44 aC", en Aufstieg und Niedergang der Römischen Welt. Von den Anfängen Roms bis zum Ausgang der Republik. Vol. I, (Walter de GruyterBerlin-New York, 1973), pp. 313 ss. BECERRA OLIVA, G., op.cit., pp. 179 ss.

6 PACCHIONI, G., Breve Historia del Imperio Romano. (Madrid, 1944), pp. 143 ss. PARIBENI, R., op. cit, pp. 198 ss y, en especial, 201 ss. PAIS, E., op. cit., pp. 346 ss. CÀSSOLA, F., - LABRUNA, L., Linee di una storia delle istituzioni republicane. $2^{\mathrm{a}}$ ed. (Napoli, 1979), pp. 374 ss. CARCOPINO, J., Julio César. El proceso clásico de la concentración del poder. Trad. esp. $2^{\mathrm{a}}$ ed. (Madrid, 2004), pp. 521 ss. KAMM, A., op. cit., pp. 101 ss. ARBIZU, J. M., op. cit., pp. 307 ss. CERAMI, P., "Cesare dictador e il suo progetto constituzionale: dal consociativismo al potere personale”, en AUPA 43 (1995), pp. 427 ss.

7 La relación de César con los magistrados ordinarios puede consultarse en MASI DORIA, C., op. cit., pp. 207 ss.

8 MASI DORIA, C., op. cit., p. 211 y nota 270.

9 Desde Sila se venía utilizando la dictadura como instrumento de dominio personal. Cicerón, Phil. I, I, 3; Apiano 3 , 25; Dion Casio, 45, 51. Cfr.: DE MARTINO, F., Storia della costituzione..., op. cit., p. 47. Sobre el nombramiento del dictador y, en concreto, el de César, $c f r$.: CASCIONE, C., op. cit., pp. 94 ss y, en especial, p. 21. Sobre la relación de César con los demás magistrados, cfr.: MASI DORIA, C., op. cit., p. 209 y las fuentes bibliográficas que allí se citan. 
que alcanzó carácter vitalicio ${ }^{10}$. Así César gobernó Roma, las provincias, los ejércitos y la política exterior ${ }^{11}$. La magnitud de su poder fue tal que algunos han querido equipararlo al imperium proconsulare maius et infinitum del Principado. ${ }^{12}$

El dictador estaba planteando, de manera incipiente, una visión imperialista ${ }^{13}$. En aras de la misma, siguió un proceso de unificación política que, en cierta forma, ya se había iniciado durante las guerras sociales con la integración de los latinos y había continuado con la de los itálicos ${ }^{14}$. Faltaba dar un paso para llegar a que ambas, Roma e Italia, se fusionaran con las provincias, con lo que se evitaría la situación de privilegio de la primera; pero la fusión no llegó hasta el Principado ${ }^{15}$.

La política de César evidenciaba la progresiva disgregación de las instituciones republicanas y dejaba entrever la crisis interna de la civitas, que vio superado el fundamento de su convivencia basado hasta entonces en la relación civitas-res publica ${ }^{16}$. El modelo de CiudadEstado ya había iniciado su decadencia ${ }^{17}$.

La república aristocrática tradicional configurada por la nobilitas dejó paso a una aristocracia de base económica, los equites ${ }^{18}$, cuya riqueza les llevó a alcanzar grandes cotas de poder. Lo cual fue propiciado por el propio dictador al ampliar la clase política romana, incrementando el número de senadores con miembros de clases sociales y procedencias diversas siempre afines,

${ }^{10}$ Dion Casio 44,8,4; 46,17,5; Apiano, 2,106; Cicerón, Phil. 2,34,87; César 57,1;76,1. Además de la dictadura y del consiguiente imperio proconsular, mediante un plebiscito, se le concedió la facultad de poderse presentar candidato al consulado durante cinco años consecutivos y otros atributos todos ellos tendentes al absolutismo. Dion Casio 42,20,3; 44,4,2;44,50,1, entre otras fuentes. Cfr. BETTI, E., La crisi della republica e la genesi del principato in Roma. A cura di G. CRIFÓ (Roma, 1982), p. 433. CÀSSOLA, F., - LABRUNA, L., op. cit., pp. 320 ss. Sobre la naturaleza constituyente de Sila y de César, $c f r .:$ MASI DORIA, C., op. cit., p. 184, nota 176, y p. 207. DE MARTINO, F., Storia della costituzione..., op. cit. Vol. IV, p. 47. BECERRA OLIVA, op. cit., pp. 195 ARBIZU, J. M., op. cit., pp. 307 ss. CASCIONE, C., op. cit., pp. 21 22., entre otros.

${ }^{11}$ El acuerdo inicial se adoptó en Lucca en el año 56 a.C. Cfr.: Apiano 2,17; Cicerón, Att. 4, 8 b (a) 2 y 4,5,3. Después le siguieron otros acuerdos, hasta llegar a ostentar la dictadura perpetua en el año 44 a.C. La magnitud de los poderes de esta dictadura son absolutos porque el dictador había asumido todas las facultades que hasta entonces habían estado en manos del pueblo, las facultades de las magistraturas ordinarias y las del Senado. Sus competencias comprendían tanto el ámbito civil como el militar. Para una exhaustiva relación de las mismas. Cfr.: BETTI, E., op. cit., p. 431 ss. PACCHIONI, G., op. cit., pp. 144 ss. CÀSSOLA, F., - LABRUNA, L., op. cit., pp. 370 ss. GIUFFRÈ. V., Aspetti costituzionali del potere dei militari nella tarda "respublica”. (Napoli, 1973), pp. 63 ss. y, en especial, p. 72.

12 BETTI, E., op. cit., p. 431.

${ }^{13}$ En relación a su pensamiento político, cfr.: GELZER, M., Caesar, Der Politiker und Staatsmann. (Wiesbaden, 1960), pp. 101 ss. Sobre la política de César, cfr.: DE MARTINO, F., Storia della costituzione..., op. cit. Vol. IV. p. 365. WEISSMÜLLER, N. W., Caesars Vorstellung von seiner Regierungsform. (Muenster, 1969). MEIER, C., Die Obnmacht des allmächtigen Diktator Caesar (Munich, 1978).

${ }^{14}$ Lex Iulia de Civitate Latinis et Sociis Danda ( año 90aC) por la que se concedió la ciudadanía romana a latinii y socii italici que no hubieran tomado parte en la guerra social. Después, la Lex Papiria de Civitate Sociis Danda (año 89 a.C.) amplió la concesión de la ciudadanía a los itálicos que en el término prescrito entregaran las armas. Cfr.: TORRENT, A., voz: Lex Iulia de Civitate Latinis et Sociis Danda, en Diccionario de Derecho Romano. (Madrid, 2005), p. 607.

15 PACCHIONI, G., op. cit., p. 143. CÀSSOLA, F., - LABRUNA, L., op. cit., pp. 377. AA. VV., Lineamenti di Storia del Diritto Romano. (Coord. M. Talamanca), ${ }^{\text {a }}$ ed. (Milano, 1989), pp. 355 ss. CIZEK, E., Mentalités et institutions politiques romaines. (s/1, 1990), pp. $147 \mathrm{ss}$.

${ }^{16}$ CICERÓN, M. T., Tres discursos jurídicos. Ed. y trad. de J. M. ROYO ARPÓN. (Madrid, 2004), pp. 21 ss. En relación a la situación concreta de las clases sociales, cfr.: ALFÖLDY, G., Historia social de Roma. Trad. esp. (Madrid, 1987), pp. 120 ss.

17 DE MARTINO, F., "Il modello della cità stato", en Diritto, Economia e Società nel mondo romano. Vol. I. Diritto Pubblico. (Napoli, 1996), pp. 473 ss. TORRENT, A., La constitutio antoniniana. Reflexiones sobre el Papiro Giessen 40 I. (Madrid, 2012), pp. 33 ss.

${ }^{18}$ MASI DORIA, C., op. cit. p. 137 ss. Sobre la historia de los equites romanos, cfr.: ALFÖLDY, G., Der frührömische Reiteradel und seine Ebrenabzeichen. (Roma, 1979), citada también por DE MARTINO, F., "Sulla Storia dell'equitatus romano", en Diritto, Economia, op. cit., p. 281, en especial, nota 1, entre otros. 
de algún modo, a su persona ${ }^{19}$. Este fue uno de los hechos que contribuyó a la creación del modelo político del Estado imperialista.

Julio César quería la unidad del imperio y gobernar a todos por igual. Y, para la consecución de sus objetivos políticos, programó la realización de una serie de medidas que afectaron a diversos ámbitos, entre las que se encuentran, la de una nueva organización administrativa y la elaboración de una compilación del derecho civil que sería aplicable a todos los habitantes ${ }^{20}$.

Con la muerte del imperator ${ }^{21}$, los tiranicidas lograron truncar, momentáneamente, su política, su forma de gobierno y sus planes reformadores; pero no proveyeron quién iba a asumir el poder tras su muerte, posiblemente porque creyeron que, una vez eliminada la persona perturbadora de los principios republicanos, las instituciones retomarían su función original y que podría producirse la restauración oligárquica ${ }^{22}$. La realidad no fue exactamente así porque las instituciones por sí mismas no recobrarían sus antiguas competencias, ni los órganos extraordinarios creados por el imperator harían dejación de sus facultades si no había ningún poder político que los dirigiera expresamente hacia aquel fin. Este fue uno de los errores del plan tramado por los asesinos, quienes, lejos de conseguir sus objetivos, tuvieron que velar por su propia vida ante la situación de confusión, de desorden, de miedo y de anarquía que generó su proceder ${ }^{23}$.

Tras algún intento de hacerse con el poder de manera individual y después de tratar de solucionar sin lograrlo toda la conflictividad existente, los propios tiranicidas, que, como se puntualizará más adelante, fueron amnistiados por el Senado a propuesta de Marco Antonio, Planco y Cicerón ${ }^{24}$, le pidieron al propio cónsul Marco Antonio y a Lépido, nombrado por César magíster equitum, que restauraran la República ${ }^{25}$. Los planes del dictador pronto tuvieron continuación al asumir Marco Antonio el poder, apoyado militarmente por Lépido, a quien le prometió el pontificado máximo ${ }^{26}$. Se hizo con el erario público ${ }^{27}$ y centró su interés, especialmente, en los proyectos futuros que tenía previstos Julio César y que figuraban en un memorandum ${ }^{28}$. Estos

${ }^{19}$ PARIBENI, R., op. cit., p. 356. CIZEK, E., op. cit., pp. 147.

${ }^{20}$ Ibid.; D.1,2,44 (Pomp., lib. sing Ench). Cfr.: PARIBENI, R., op. cit., p. 199. La elaboración de la compilación, pudo encargarse al jurista Aulo Ofilio, que contó con gran prestigio, no sólo por ser amigo personal de César y auditor de Servio Sulpicio Rufo, sino por su auctoritas personal y por su formación helenística todo lo cual quedó reflejado en su trabajo, en especial, el realizado sobre el orden del edicto del pretor. Cfr.: DOMINGO, R., "La jurisprudencia romana, cuna del Derecho", en Revista Jurídica. Facultad de Jurisprudencia y Ciencias Sociales y Políticas. Universidad de Santiago de Guayaquil. Ecuador. [Revista Jurídica on line]. 2013, p. 5 y 7. CERAMI, P., "Il sistema Ofiliano", en La Codificazione nel Diritto dall'antico al Moderno. (Coord. E. Dovere). (Napoli, 1998), pp. 83 ss.. Sobre la referencia a las vigésimas en la obra de Ofilio, cfr: ORTUÑO PEREZ, M. E., “Aulo Ofilio: De legibus vicensimae primus conscribit”, pendiente de publicación. Sobre las reformas efectuadas por César, cfr.: CARCOPINO, J., op. cit., pp. 520 ss. ROLDÁN, J. M., Historia de Roma. T. I. La República Romana. $5^{\text {a }}$ ed. (Madrid, 1999), pp. 625 ss.

${ }^{21}$ Hasta entonces, el título de Imperator sólo había sido utilizado por los Jefes militares victoriosos. Entre otros, cfr.: TORRENT, A., voz: Imperator, en Diccionario..., op. cit., p. 433.

22 BETTI, E., op. cit., 456 ss. ARANGIO RUIZ, V., Historia del Derecho de Roma. $4^{\mathrm{a}}$ ed. Trad. esp. (Madrid 1980), pp. 249 ss.

23 Apiano describe de manera pormenorizada los acontecimientos, $c f r .:$ Apiano 3,2-3; 3,4 y 3,5.

${ }^{24}$ Plutarco, Brut. 19; Ant. 14,2. Cic. 42,2.

${ }^{25}$ Cicerón, Phil. 2,89. Cfr.: BETTI, E., op. cit., p. 457.

${ }^{26}$ Dion Casio 44,53,6. Cfr.: TONDO, S., Profilo di storia costituzionale romana. (Milano, 2010), p. 214.

${ }^{27}$ Cicerón, Phil.2,93; 5,11.15; 8,26,12,13. Apiano 3,52,215 (14-15); 54-224; Vell. 2,60,4. Todo ello citado en: BETTI, E., op. cit., p. 457 , nota 8 .

${ }^{28}$ Sin perjuicio de lo expresado, hay que considerar también que Cicerón pronunció un discurso en el Senado contra Marco Antonio en el que decía que debían derogarse todas las leyes porque habían sido aprobadas con violencia; entre ellas, la ley de dictadura in perpetuum tollenda, que entendía que debía votarse de nuevo. Cfr.: Cicerón, Phil. 5,4,10. La oposición de Cicerón se refería a la dictadura y todo lo aprobado por ella debía derogarse por haberlo aprobado un órgano ilegal. Sobre esta problemàtica, cfr.: DE MARTINO, F., "Sugli aspetti giuridici...”, op. cit., pp. 515 ss. 
escritos se conocen también como Acta Caesariana $^{29}$ y le fueron entregados por su viuda junto al patrimonio privado de aquél ${ }^{30}$.

A imagen del dictador, Marco Antonio realizó algunas reformas; una parte de ellas estaban amparadas en lo que constaba efectivamente en el Acta y otras eran de su propia iniciativa, pero falsamente atribuidas a César. En realidad, la mayor parte de las mismas, las llevaba a cabo para ganarse voluntades ${ }^{31}$. Promulgó también una serie de leyes tendentes a hacer recaer en su persona el poder que le permitiera ejercer la dirección y el gobierno de las provincias más estratégicas $^{32}$.

Marco Antonio logró un acuerdo político con el Senado en virtud del cual se aprobó la conformidad del Acta Caesariana y la amnistía de los asesinos del dictador. ${ }^{33}$ Todo ello se hizo en aras de mantener una paz más aparente que real. Marco Antonio no cesó en su empeño e hizo ratificar por el pueblo el senadoconsulto por el que se había confirmado el Acta citada, mediante una lex data, la Lex de Actis Caesaris Confirmandis ${ }^{34}$ (17 de marzo del año $44 \mathrm{aC}$ ), en la que se obvió el trámite del trinundinum, y, por consiguiente, no se respetó el plazo de tiempo que debe mediar entre la propuesta pública formal de la ley y su aprobación ${ }^{35}$. En la confirmación se hizo especial mención a las leyes coloniales agrarias ${ }^{36}$ y se incluyó en el Acta no sólo lo que César había dejado escrito, sino también las disposiciones no publicadas ${ }^{37}$. La condición que había ostentado el dictador permitía que su voluntad bastara por sí misma, sin necesidad de tener que

${ }^{29}$ Apiano 2,125. César recogió por escrito su plan estratégico de actuación, que se ha conocido como Acta Caesariana. La doctrina, apoyándose en las noticias aportadas por Cicerón, Apiano y Dion Casio y en atención a los hechos acontecidos, postula una interpretación amplia de dicho escrito, en el sentido de considerar incluída en ella, no sólo lo realmente escrito sino todas aquellas disposiciones y decisiones adoptadas por César aunque no se hallaran en el texto. La legitimadad de todo ello vendría dada por las facultades del dictador, que tenía pleno control del ejército y, de ahí, que se le atribuyera el calificativo de Imperator. Hasta entonces, este término se había utilizado para designar al magistrado que estaba al frente del ejército vencedor. Podía también decidir por sí mismo si se entraba en guerra; y tenía el poder absoluto sobre el erario público. Su potestas censoria le permitía, no sólo el control de las finanzas públicas, sino también la imposición fiscal. Cfr.: BETTI, E., op. cit., p. 460 y, en especial, las fuentes literarias citadas en las notas 32 y 33. CAPOGROSSI COLOGNESI, L., Storia di Roma, tra diritto e potere. (s/l, 2009), pp. 272 ss.

${ }^{30}$ En relación al erario público, cfr.: Apiano, 3,52,215 (14-15); 3,54,224; Dion Casio 45,24,1. En relación a la documentación y el patrimonio de César, cfr.: Apiano, 2,125,524; 3,5,16 (4-5), 17,63; Dion Casio, 44,53,2-3; 46,23,1-2; Plutarco, Ant. 15; Ciceron, Phil. 2,35; 3,30. Cfr.: PACCHIONI, G., op. cit., p. 150. BETTI, E., op. cit., p. 457.

31 Apiano 3,5. Cfr.: por ejemplo, la Lex Iulia de Exilibus Revocandis, que fue promulgada por Marco Antonio en aplicación del Acta Caesariana, con la que hizo regresar a Roma a diversos exiliados. Cicerón, Phil. 2,38,98; 5,4,11. Dion Casio 45,25,2; 46,15,2.

32 De entre la estas leges pueden resaltarse, entre otras, la Lex Antonia de Permutatione Provinciarum que se votó con oposición del Senado en los comitia tributa y que dejó de aplicarse después de su consulado. En ella se asignaron a Marco Antonio los territorios de la Galia Cesalpina y una parte de la Transalpina. Cfr.: Cicerón, Phil.1,10, 25-26. GUTIERREZ ALVIZ, F., voz: Lex Antonia Iudiciaria, en Diccionario de Derecho Romano. (Madrid, 1982), p. 326. La Lex Antonia Iudiciaria, por la que Marco Antonio estableció que se reclutaran entre excenturiones la tercera decuria de jueces. Cfr.: ROTONDI, G., op. cit., p. 431. La Lex Iulia de Civitate Siculis Danda, publicada tambien por Marco Antonio, por la que se concedía la ciudadanía a los sicilianos. Todas estas leyes fueron promulgadas en el año 44 a.C., y se plantearon como ejecución del Acta Caesariana. Cfr.: ROTONDI, G., op. cit., pp. 429 ss.

33 Apiano 2, 133-134,135,563. Dion Casio 44,34,1; 45,23,4. Cicerón, Phil. 1,2,16. Cfr. TONDO, S., op. cit., p. 216. BETTI, E., op. cit., p. 460. DE MARTINO, F., Storia della costituzione..., op. cit. Vol.IV. pp. 46 ss.

34 Apiano 2,135; 3,5 y 22; Dion Casio 44,53,2; 45,23. Cicerón, Phil. 5,10; 1,25,2,6. Cicerón, Phil. 5,3,8; 5,4,10; 1,7,16; 1,10,24; 2,39,100; 6,2,3; 10,8,17; 13,15;31: Cicerón, ad fam., 12,14,6. Cicerón, ad att., 14,9,2; 14,12,1. Cfr.: ROTONDI, G., op. cit., pp. 429-430.

${ }^{35}$ ROTONDI, G., op.cit., pp. 123 ss. Cosa distinta al caso que contemplamos es el trinundinum referido en las XII Tab. a los casos de insolvencia del deudor en los procesos civiles. Cfr.: TORRENT, A., voz: Trinundinum, en Diccionario, op. cit., p. 1392.

36 Apiano 2,135. Cfr.: BETTI, E., op.cit., p. 458.

37 Apiano 2,134,562 (18-19); Apiano 2, 135,563 (4-5); Apiano3,5,16 (3-4); Dion Casio 44,53,2. 
recurrir al cumplimento de requisito formal alguno ${ }^{38}$. El propio Marco Antonio mandó que una serie de leges fueran consideradas como parte integrante del Acta Caesariana ${ }^{39}$.

Urgía a Marco Antonio la confirmación del Acta para poder legitimar su conducta en base a la misma. Pero pese haber obtenido la legitimación formal no logró evitar las suspicacias y desconfianzas generadas en relación a su particular aplicación. Marco Antonio necesitaba ganarse la confianza del Senado y para ello, tres meses después de su confirmación (el 3 de junio), él mismo promovió que algunos tribunos propusieran y aprobaran un plebiscito -Plebiscitum de Caesaris Actis cognoscendis cum consilio ${ }^{40}$ - con el objeto de confiar el examen del Acta Caesariana a los dos cónsules, que actuarían asistidos por una comisión, dado que el Acta aún no había sido publicada ${ }^{41}$. Pero todo ello no fue más que una estrategia para privar al Senado de un control efectivo.

La apertura del testamento de César provocó que apareciera en la escena política Octavio, que había sido adoptado por el dictador ${ }^{42}$-y, más tarde, cuando accedió al consulado adoptó su propia onomástica, C. Iulius Caesar Octavianus ${ }^{43}$-, y a quien designó también como su heredero. Octavio, a partir de entonces, no se conformó con adquirir simplemente su patrimonio, que en principio le fue negado por Marco Antonio, sino que quiso hacerse con el poder, sin importarle que, para ello, tuviera que incurrir en la ilegalidad y correr el riesgo de que pudieran acusarle de alta traición, por haber constituido un ejército privado que estaba exclusivamente bajo su mando, a cambio de recibir una remuneración económica ${ }^{44}$.

No es este el lugar para detallar la actuación que llevaron a cabo Marco Antonio y Octaviano. Éstos gozaban del apoyo del sector político de los cesarianos o populares, quienes les ayudaron a hacer frente a los opositores -los republicanos o partido senatorial- entre los que se encontraban los tiranicidas. Fueron muchas las estrategias y las alianzas adoptadas por Marco Antonio y por Octaviano, el primero para mantenerse en el poder y el segundo para hacerse con él ${ }^{45}$. Los méritos que podían alegar radicaban en sus propias habilidades y en el apoyo del ejército. Se trataba de una lucha personal, en la que cada uno pretendía continuar el régimen político de César, haciéndose con el poder personal, tiránico y de carácter revolucionario que éste tuvo. Era el preludio de una nueva guerra civil que no llegó a iniciarse de inmediato, por una aparente reconciliación que no se mantuvo mucho tiempo ${ }^{46}$. Momentáneamente se optó por recurrir al pacto.

\footnotetext{
38 BETTI, E., op. cit., p. 460.
}

${ }^{39}$ Esta leges fueron: Lex Iulia de insula Creta; Lex Iulia de Exilibus Revocandis; Lex Iulia de Civitate Siculis Danda; Lex Iulia de Rege Deiotaro; entre otras, todas ellas del año 44 a.C., y pueden consultarse en: ROTONDI, G., op.cit., pp. $430 \mathrm{ss}$.

40 Apiano 3,5,16 (2-4); 22,81 (17-18); Dion Casio 44,53,2;45,23,5.

${ }^{41}$ Dion Casio 44,53,4; Cicerón, ad att. 16,16,11. Cfr.: ROTONDI, G., op. cit., p. 432-433 y las fuentes literarias que allí se citan.

42 Apiano 3,14; Suetonio, Caes. 83. Se dió así una continuación al nombre familiar, a la vez que se conseguía el apoyo de la clientela del adoptante en favor del adoptado.

${ }^{43}$ Cfr.: Apiano 3,94; Dion Casio 46,47,4. En adelante Octaviano. Era una adoptio in familiam nomenque. Al tratarse de una adopción testamentaria, por si misma no implicaba una sucesión per universitatem, sino que para la transmisión del patrimonio era necesario, como ocurrió en este caso, que el causante, a saber César, le dejara su patrimonio. La eficacia de esta adopción se centraba en el nomen. Cfr.: Entre otros, ALBERTARIO, E., "In tema di adozione romana", en Studi Albertario 1 (1953), pp. 131 ss. LEMOSSE, M, "L'adoption d'Octave et ses rapports avec les regles traditionelles du droit civil", en Studi Albertario I (1953), pp. 369 ss. TONDO, S., op. cit., p. 219, nota 38. Cfr.: También: Apiano 3,29. Pone en cuestión este tipo de adopción, DE MARTINO, F., Storia della costituzione..., op. cit., p. 90. SHOTTER, D., The Fallo f the Roman Republic. (London-New York, 1994), p. 87.

${ }^{44}$ GIUFFRE, V., Homines militares e status rei publicae. Torsioni di una constituzione. (Napoli, 2013), p. 90.

45 BETTI, E., op. cit., pp. 474 ss.

${ }^{46}$ La exposición pormenorizada de los hechos puede consultarse en BETTI, E., op. cit., pp. 498 ss. y PARIBENI, R., op. cit., pp. 268 ss. 
El acuerdo generó de nuevo un poder excepcional, al que legalmente se le confirió una duración limitada ${ }^{47}$, imitando lo que, en un principio, había hecho su antecesor César. Y, a la vez, se mantenía, aunque sólo fuera como estrategia, un elemento propio y significativo de la República ordinaria ${ }^{48}$; se creó el segundo triunvirato, en el que los triunviros, Marco Antonio, Octaviano y Lépido, se hicieron con poderes absolutos, tanto en el ámbito de gobierno como en el militar (imperium proconsulare maius), que deberían ejercer de manera consensuada, concentrando en sus manos la obligación de reordenar la res publica y restaurar el orden republicano, sin limitación alguna ${ }^{49}$. No obstante ello, los triunviros no pretendían realmente dicha restauración. Como César, tuvieron claro que debían contar con el ejército, porque el mismo estaba al servicio de la política, y ésta dependía para todo de aquél.

La constitución del triunvirato no conllevó el cese de las confrontaciones políticas. Se libró una nueva guerra civil ${ }^{50}$, la guerra de Perusia (años $41 \mathrm{aC} .-40$ a.C.), en la que el cónsul Lucio Antonio, hermano de Marco Antonio, apoyado por la esposa de éste último, Fulvia, con quien se acababa de casar, reclutaron unas legiones para enfrentarse al enemigo político de su marido y hermano, Octaviano.

Esta guerra escondía su auténtica finalidad. El cónsul manifestaba abiertamente que el triunvirato había cumplido ya su cometido y que debía restaurarse el funcionamiento normal de la República. Pero la realidad era muy distinta; su verdadero propósito era levantar a la población contra Octaviano para que su hermano se hiciera con el poder absoluto. En realidad, querían acabar con su colega que a la vez era su enemigo político. Venció Octaviano y tras la muerte de Fulvia en el exilio, el mismo año 40 a.C., Marco Antonio y Octaviano firmaron el tratado de Brindisi, que puso fin a esta contienda.

En este mismo año, ambos triunviros retomaron la confrontación contra Sexto Pompeyo, cuyo posicionamiento político a favor de la clase senatorial y su control sobre el ejército naval, le habían llevado ya a enfrentarse con César. Los triunviros precisaban hacerse con dicho control para garantizar el abastecimiento de Roma y para poder detentar la defensa naval. Sus contiendas duraron varios años en los que del tratado de paz (paz de Miseno año 39 a.C. ${ }^{51}$, pasaron a nuevas guerras en las que las victorias se iban alternando con las derrotas. Los acontecimientos se fueron sucediendo hasta llegar a la derrota de Pompeyo y a la expulsión de Lépido del triunvirato ${ }^{52}$.

En definitiva, desde el asesinato de César se instauró un régimen militarizado, en el que la fuerza armada estaba en manos de los triunviros, como lo estaba también cualquier acto propio del régimen constitucional ordinario, que por las características de su poder quedaban exclusivamente sometidas a su voluntad. Planteamiento que tuvo solución de continuidad cuando Octaviano y Marco Antonio desarrollaron una acción conjunta para repartirse el poder ${ }^{53}$.

${ }^{47}$ D’ORS, A., “Cicerón, sobre el Estado de excepción”, en Ensayos de Teoría Política (Pamplona, 1979), p. 168.

${ }^{48}$ LAFFI, V., "Poderes triunvirales y órganos republicanos", en Sociedad y política en la Roma republicana. (Siglos III a I a.C.). (Pisa, 2000), pp. 297 ss. ID., "Il triumvirato costituente alla fine della repubblica romana", en Scritti in onori di M. A. Levi (Como, 1993), pp. 37 ss. SHOTTER, D., op. cit., pp. 93 ss.

${ }^{49}$ La legitimación de dicho acuerdo provino de la Lex Titia de Triunviris Rei Publicae Constituendae, de 27 de noviembre de 43 a.C., que les reconoció el status de triunviri rei publicae constituendae por 5 años. Se pretendía conquistar el poder en contra de la aristocracia senatorial, que apoyaba a los asesinos de César y que quería hacerse con el gobierno de Roma. Cfr.: DE MARTINO, F., “Sugli aspetti giuridici...”, op. cit., pp. 515 ss.

50 Destaca la guerra como un potente motor económico romano: MASI DORIA, C., Modelli giuridici, prassi di cambio e "medium" linguistico. Un itinerario dell' espansionismo romano. (Napoli, 2012), pp. 53 ss.

${ }^{51}$ En el año 38, Octaviano asumió el praenomen de imperator. Fue sancionado por el Senado en el 29 a.C., cf.: GIUFFRÈ, V., Homines..., op. cit., p. 92, entre otros.

52 Un resumen pormenorizado de los acontecimientos puede consultarse en GIUFFRÈ, V., Homines..., op. cit., p. 92 ss. Para un tratamiento más amplio, cfr.: DE MARTINO, F., Storia della costituzione..., op. cit., pp. 71 ss.

${ }^{53}$ DE MARTINO, F., Storia della costituzione..., op. cit. Vol. IV. pp. 73 ss. 
Los acuerdos basados en criterios de oportunidad e interés político estaban a la orden del día. No es pues de extrañar, que quien en algún momento hubiera pactado con una corriente política, después luchara contra ella. Se inició un período de los más convulsos y complejos de la historia de Roma ${ }^{54}$ en el que intentaban convivir los principios republicanos con las luchas por hacerse con el poder personal, libradas entre los partidarios de las diversas corrientes políticas, que pactaban y se aliaban con quien mejor les pudiera facilitar el acceso al poder o les pudiera mantener en él, sin ningún tipo de escrúpulo ni moral ni ideológico. Las luchas eran políticas y se ponían todos los medios de la Republica, incluso los económicos, al servicio de las mismas ${ }^{55}$. Fue un período de confrontación de intereses y de guerras civiles, en el que el poder se ejercía de hecho, ya que se trataba de un poder militar.

La lucha contra Sexto Pompeyo ocasionó grandes gastos militares y, a la vez, constituyó un grave peligro para el abastecimiento de alimentos a la población, porque su posición estratégica le permitía controlar y, normalmente, saquear, las flotas que transportaban alimentos procedentes de Egipto y de las provincias orientales ${ }^{56}$. Se llegó a padecer hambruna.

La situación financiera era ruinosa. El ejército tenía una implicación directa en la política y resultaba imprescindible, y los gastos de su mantenimiento eran muy elevados y difíciles de sufragar. Los gastos del Estado sobrepasaban con creces a sus ingresos por lo que se vivía una situación inflacionaria grave y la población no podía soportar más cargas ${ }^{57}$.

La República vivía sus últimos momentos; la situación era límite. La sociedad estaba sometida a la tiranía y al despotismo de quienes ejercían el poder político que, en estos momentos, estaba vinculado al poder militar. Dominaba la arbitrariedad y la fuerza.

El triunvirato no se disolvió hasta entrado el año 33 a.C.

\section{LA SITUACIÓN INFLACIONARIA Y EL EMPEÑO POR SUPERARLA}

El avituallamiento de las ciudades se vio interrumpido porqué la mayor parte de alimentos llegaban a Roma por vía marítima. Los mercaderes, tanto de Oriente como de Occidente, no se atrevían a navegar por miedo a las tropas de Pompeyo que dominaban los litorales de ambas costas. La población romana estaba azotada por la hambruna; los alimentos escaseaban y su precio se había incrementado desmesuradamente.

La población estaba exaltada ante esta situación a la que se había llegado como consecuencia de los enfrentamientos de Octaviano y Marco Antonio con Pompeyo. Marco Antonio era proclive a solucionar las contiendas; pero no así Octaviano que no cedió ante las presiones del primero. Se le pidió que pusiera fin cuanto antes a la guerra, ya que no había dinero para mantenerla. Una manera de proveer al erario fue la promulgación de un edicto en el que se impuso la obligación a los propietarios de los esclavos que aportaran por cada uno de ellos la mitad de las veinticinco dracmas fijadas para la guerra de Casio y Bruto ${ }^{58}$.

${ }^{54}$ Ibid, pp. 43 ss.

55 DE MARTINO, F., "Motivi economici nelle lotte dei populares”, en Diritto. Economia..., op. cit., pp. 299 ss., en especial p. 300.

${ }^{56}$ Los triunviros decidieron acabar la guerra por los riesgos que comportaba la misma y, al año siguiente de iniciarse, se firmó el Pacto de Miseno (39 a.C.).

${ }^{57}$ La situación inflacionaria provenía ya del gobierno de César. Cfr.: TORRENT, A., "Inflación y proceso en la legislación municipal", en RIDA 29 (1972), p. 465.

${ }^{58}$ Dion Casio 47,17,4. NICOLET, C., Tributum. Recherches sur la fiscalité directe sous la Republique romaine. (Bonn,1976), p. 89. 
Incidía en esta crisis económica el gran desequilibrio existente entre las clases sociales. La aristocracia y en especial la nueva aristocracia constituida por los equites, poseedores de cuantiosas fortunas, se beneficiaron ampliamente de las riquezas obtenidas por Roma como consecuencia de la anexión imperialista de los nuevos territorios. Se extendieron las propiedades latifundistas que los terratenientes explotaban con sus esclavos. Frente a ellos una masa de población empobrecida era víctima de las luchas políticas y de las guerras civiles ${ }^{59}$. Se produjo una emigración hacia la ciudad por parte de los campesinos perjudicados por el latifundismo y, una vez allí, fueron utilizados como grupos de presión por las diferentes tendencias políticas.

La economía era totalmente inestable y desequilibrada; mucho de ello fue heredado de la política de César cuyas medidas llevaron a una situación de completa inflación ${ }^{60}$.

Las confrontaciones generaron gastos en exceso que las arcas públicas no podían sufragar; en muchas ocasiones se saquearon los patrimonios de muchos ciudadanos para llenar las cajas de los jefes militares o para repartirlos entre los soldados victoriosos y veteranos del ejército. La venta en pública subasta del sobrante del botín una vez honrado el cónsul o el general victorioso $^{61}$ se hacía de manera fraudulenta, por cantidades irrisorias para favorecer a los sujetos proclives al poder ${ }^{62}$.

Se generó un auténtico conflicto de intereses entre los veteranos del ejército y los pequeños y medianos propietarios rurales, porque caía sobre ellos las asignaciones de tierras a dichos veteranos por haberse agotado prácticamente el ager publicus. Estas asignaciones se convirtieron en auténticas confiscaciones ${ }^{63}$.

Desde la reforma de Mario del año 107 a.C. ${ }^{64}$, el ejército dejó de identificarse con el populus romano y también dejó de ser un honor de los cives el formar parte del mismo. Ya no tenía el carácter ciudadano que le había significado hasta entonces y ya no se luchaba por la res publica. El tipo de ejército compuesto por campesinos y por propietarios itálicos fue dejando paso a un ejército integrado por mercenarios profesionales movidos por sus propios intereses y que rendían tributo a quienes les habían contratado ${ }^{65}$. Estaban al mando los generales, también profesionales, quienes, poco a poco, además del mando militar, fueron asumiendo el mando político, perjudicando con ello la posición del Senado y de los Comicios. Los militares eran conscientes de la importancia de la labor que debía cumplir el ejército, tanto desde el punto de vista interno, con su participación en las diferentes guerras civiles, como externo, ya que también debían contribuir a crear y mantener el Imperio que se estaba formando.

\footnotetext{
59 POLVERINI, L., “L'aspetto sociale del passaggio dalla repubblica al principato”, en Aevum 38 (1964); 39 (1965).

${ }^{60}$ Las guerras constantes, las numerosas obras públicas y el incremento de las pagas de los soldados a cargo del erario del Estado fueron factores determinantes para llegar a esta situación. Cfr.: TORRENT, A., "Inflación...", op. cit., pp. 449 ss, y en especial, p. 465.

${ }^{61}$ ROSTOVTZEFF, M., Historia Social y Económica del Imperio Romano. I. Trad. esp. (Madrid, 1937), pp. 66 ss. DI RENZO, F., La finanza antica. (Milano, 1955), pp. 97 ss.

${ }^{62}$ Una prueba de ello se encuentra en César, que aunque quiso corregir los desmanes que se producían en este sentido, estableciendo que los bienes se vendieran según su valor real, él mismo favoreció que Marco Antonio, su favorito, adquiriera todos los bienes de Pompeyo. Cfr.: DI RENZO, F., op. cit., p. 151.

${ }^{63}$ NEUMANN, A., voz: "Veterani", en PW. Supl. 9 (Stuttgar, 1962), pp. 1597 ss. TALAMANCA. M., Lineamenti di Storia del Diritto Romano. (Milano, 1989), pp. 367.

${ }^{64}$ Mario realizó la reforma en el año 107 a.C. En relación a la misma, puede consultarse, entre otros, MARIN Y PEÑA, M., Instituciones Militares Romanas. (Madrid, 1956), pp. 47 ss. GABBA, E., "El consenso popular a la política expansionista romana (siglo III-II a.C.)", en GABBA, E \& LAFFI, V., Sociedad política en la Roma republicana (Pisa, 2000), pp. 209 ss. GIUFFRÈ, V., Homines (...), op. cit., pp. 29 ss. BLANCH NOUGUÉS, J. Ma ., "Una visión históricojurídica sobre el ejército romano", en RGDR 17 (2011), pp. 1 ss.

${ }^{65}$ Giuffrè puntualiza que aunque el ejército fuera profesional, no por ello tenía que ser mercenario. Cfr.: GIUFFRÈ, V., Homines..., op. cit., p. 43.
} 
A partir de César, el ejército era permanente y estaba constituido, normalmente, por personas sin bienes a los que se les pagaba una remuneración ordinaria ${ }^{66}$. La pertenencia al ejército era su modus vivendi y luchaban movidos por la compensación que iban a recibir, en dinero y en asignación de tierras, cuando finalizara la contienda. Surgió lo que Guiffrè denomina patronato, por haberse creado situaciones de dependencia vital entre el jefe militar y su ejército ${ }^{67}$. Se generó el clientelismo militar que se incorporó al de carácter civil ya existente ${ }^{68}$. Apareció también el caudillaje $^{69}$ y las fuentes literarias dan cuenta de la existencia de ejércitos privados y del temor que éstos generaban a la propia constitución republicana ${ }^{70}$.

El ejército aún siendo permanente, no era unitario, ya que cada triunviro tenía bajo su autoridad un número de legiones. Se identificaba con el personaje público que lo había formado $^{71}$. Y fue también una actividad altamente rentable para sus miembros, ya que tenían en sus manos la fuerza que utilizaba cada sector para hacer valer sus pretensiones.

La individualización y la autonomía fue tal que la proclamación de los triunfos del ejército dejó de seguir el cauce constitucional ordinario y ser declarado por el Senado, para pasar a ser por la aclamación del respectivo ejército ${ }^{72}$.

El poder militar fue creciendo a lo largo de los años, a la vez que se incrementó su relación con el poder político hasta pasar a ser un elemento fundamental del mismo. Los jefes militares se convirtieron en un poder fáctico y la satisfacción de sus necesidades y de su lealtad se tradujo en un problema de Estado. En definitiva, el ejército se convirtió en un grupo privilegiado a quien el poder político era consciente de que debía contentar y la prueba de ello se encuentra en algunas de las medidas adoptadas ${ }^{73}$.

Entre estas medidas están el reparto y la asignación de tierras a los veteranos ${ }^{74}$. Los triunviros y, más en concreto, Octaviano, en el año 41 a.C., fijó las reglas de reparto y centralizó la dirección del mismo en Roma ${ }^{75}$. Siguiendo la política iniciada por César ${ }^{76}$, Octaviano dividió todo el territorio que tenía que ser objeto de adjudicación, de tal manera que le permitía, por un lado, saber dónde ubicar las instalaciones militares y, por otro, la porción de tierra que podría asignarse a cada soldado; tierras, que eran elegidas entre las más fértiles ${ }^{77}$. Esta división formaba parte de una estrategia política con la que los triunviros se aseguraban la fidelidad del ejército, al poder prometer exactamente lo que podría recibir cada soldado.

En todo caso, se favoreció al ejército en detrimento de la población. Y así, en caso de interesar alguna tierra de propiedad privada, no existía inconveniente alguno en expropiar a sus titulares.

\footnotetext{
${ }^{66}$ GIUFFRÈ, V., Aspetti..., pp 21 ss. Más tarde, con Augusto, se creó el peculium castrense para retribuir a los filius familiae que formaran parte de las legiones.

${ }^{67}$ GIUFFRE,V., Aspetti..., op. cit., pp. 23 ss. ID., Homines..., op. cit., pp. 40 ss.

${ }^{68}$ MOMMSEN, T., Compendio del Derecho Público Romano. $1^{\mathrm{a}}$ ed. Argentina (Buenos Aires, 1942), pp. 27 ss. DENIAUX, E., Clientèles et povoir à l'èpoque de Cicerón. (Roma, 1993), pp. 287 ss.

${ }^{69}$ FUENTESECA, P., Historia del Derecho Romano. (Madrid, 1987), p. 235.

${ }^{70}$ Cfr.: Cicerón, Phil.10,5,12; Apiano, 1,2,7; 1,34,151; 4,93,39, entre otras.

${ }^{71}$ GIUFFRÈ, V., Homines..., op. cit., p. 67.

${ }^{72}$ GIUFFRÈ, V., Aspetti..., op. cit.,, pp. 43 ss.

73 Alude a estas medidas de los triunviros: Apiano 4,5.

74 ROSTOVTZEFF, M., op. cit., pp. 70 ss.

75 Apiano, 5,16,66

${ }^{76}$ Lex Iulia Agraria (59 aC), además de la Lex Iulia Municipalis (49-44 a.C.), que se discute si fue de César o de Augusto. Cfr.: Entre otros, TORRENT, A., Voz: Lex Iulia (Caesaris) Agraria, en Diccionario, op. cit., p. 607. ID., Lex Iulia (Caesaris) Municipalis., p. 609.

77 HINRICHS, F. T., Histoire des Institutions Gromatiques. (París, 1989), pp. 66 ss.
} 
El carácter político del reparto era indudable y no importó que los titulares de las fincas rústicas habitaran en Roma. La asignación de las tierras creaba con los beneficiarios de las mismas una especie de relación de protección.

Estas medidas estaban orquestadas por el poder político en aras de la obtención de un mayor apoyo de quien era el elemento fundamental para hacer valer sus pretensiones, con el empleo de la fuerza si era necesario.

De esta suerte, los gastos de mantenimiento del ejército no sólo azotaron fuertemente al erario del Estado, sino que también afectaron a los patrimonios de los ciudadanos. Pero el ejército era imprescindible y para intentar sufragar su coste se acudió a la exacción fiscal ${ }^{78}$ y a la adopción de medidas de carácter político como la confiscación de la totalidad de los bienes de los proscritos.

El poder constituyente de los triunviros estaba fuera del orden constitucional ordinario de la República, y por ello su actuación era completamente libre, sin ataduras propias del régimen, a pesar de que mantuvieron el funcionamiento de los órganos constitucionales republicanos, aunque sometidos a su control. Su particular situación no sólo les legitimaba para dirigir todo tipo de actividad política, sino que también podían actuar, de igual modo, sobre las finanzas públicas, a la vez que ostentaban facultades legislativas ${ }^{79}$.

Desde la perspectiva fiscal, utilizaron dichas facultades para adoptar las medidas que en este orden que fueran necesarias para poder hacer frente a los ingentes gastos militares ${ }^{80}$. El sistema financiero tenía su fundamento en la tributación, y ante la precariedad de la situación en la que se encontraban, se optó, como había sido hasta entones, por la imposición de gravámenes sobre elementos patrimoniales concretos y sobre las actividades privadas en las que la administración pudiera ejercer algún tipo de control. La fiscalidad estaba concebida como un instrumento de política financiera ${ }^{81}$ y estaba prevista para hacer frente a dichos gastos y para satisfacer las necesidades extraordinarias del Estado, ya que su imposición estaba en función de aquellos menesteres $^{82}$.

Precisamente fue la necesidad económica la que llevó a recuperar la imposición del tributo del que se habían servido en otro tiempo de la República, en todos aquellos casos en los que

${ }^{78}$ GABBA, E., "Esercito e fiscalità a Roma in età repubblicana", en Armées et fiscalité dans le monde antique. (París, 1976-1977). Y también, ID., Esercito e società nella tarda repubblica romana. (Firenze, 1973).

${ }^{79}$ MOMMSEN,T., op. cit., pp. 257 ss., entre otros.

80

En circunstancias normales, durante la República la imposición fiscal era competencia de las asambleas populares, que procedían a su aprobación previa propuesta del magistrado competente, después de haberlo sometido a información pública. Cfr.: FERNÁNDEZ DE BUJÁN, A., Derecho Público Romano. $17^{\mathrm{a}}$ ed. (Madrid, 2014), pp. 335. En relación a la situación concreta del segundo triunvirato, cfr.: BETTI, E., op. cit., pp. 502 ss. Vid., HUMBERT, G., Saggio sulle finanze e sulla contabilità pubblica presso i romani. Trad. Ital. (s/l, reed. 1886), pp. 13 ss. Una visión general de la fiscalidad republicana, $c f r$.: SPAGNUOLO VIGORITA, T.- MERCOGLIANO, F., voz: “Tributi (dir. rom.)", en ED 45 (1992), pp. 88 ss.

${ }^{81}$ FERNÁNDEZ DE BUJÁN, A., Derecho Público Romano, op. cit., p. 326. ID., "Ius fiscale: Principios informadores del sistema tributario romano", en Principios Generales del Derecho. Antecedentes históricos y horizonte actual. Coord. F. Reinoso Barbero. (Madrid, 2014), pp. 113 ss.

${ }^{82}$ HUMBERT, G., op. cit., p. 14. APARICIO PÉREZ, A., "Aportaciones del Derecho romano a la fiscalidad moderna. I.", en RGDR 12 (2009), p.13, citado también por FERNÁNDEZ DE BUJÁN, A., "Ius fiscale: Instrumentos de política financiera", en Iura 58 (2010), p. 14 nota 34. ID., "Ius fiscale: Principios...", op. cit., pp. 109-130. 
la guerra había generado gastos extraordinarios ${ }^{83}$. Se trata del tributum ex censu $^{84}$, que no se había aplicado desde el año 167 a.C. ${ }^{85}$. Se reinstauró por el Senado a instancia de Cicerón durante la guerra civil contra Marco Antonio (junio del año 43 a.C. $)^{86}$.

Era un impuesto extraordinario de carácter directo, de imposición no regular, ya que se creaba en relación a hechos concretos, y de naturaleza patrimonial, que gravaba de manera proporcional el capital declarado por los ciudadanos. El cálculo se hacia en base a la valoración obtenida del patrimonio dado a conocer por los propios ciudadanos en la professio censualis ${ }^{87}$. Se trataba de una contribución de guerra, impuesta en base a los gastos del ejército y de su mantenimiento, determinados con toda precisión. Y también podía aplicarse en situaciones extraordinarias ${ }^{88}$. Era un impuesto que gravaba la fortuna de los ciudadanos; nunca fue una "capitatio", porque ello hubiera implicado un signo de servidumbre que escapaba de los postulados de la concepción romana de ciudadanía ${ }^{89}$.

Como se ha dicho, se calculaba sobre la evaluación del patrimonio declarado. La proporcionalidad de las cargas estaba unida a la proporcionalidad de los privilegios de quienes debían sufragarlo, al estar determinado en función de la cuantía patrimonial ${ }^{90}$.

La doctrina no coincide a la hora de precisar si el pago de dicho tributo estaba o no sujeto a devolución por parte del Estado. Basándose en algunas fuentes literarias de diferentes épocas ${ }^{91}$, hay quienes consideran que era reembolsable, en el sentido de que, una vez satisfechos los gastos reales, si había algún excedente debía retornarse a los contribuyentes, teniendo prioridad los que más habían pagado, es decir, los más ricos ${ }^{92}$. En contra de esta interpretación se argumenta que

${ }^{83}$ El tributo de por sí, como no era un impuesto permanente, se gestionaba como una cuestión de orden administrativo que entraba dentro de las competencias de las magistraturas y del Senado. Cfr.: GUIRAUD, P.,'L'impôt sur le capital sous la Rèpublique romaine", en NRHDFE 20 (1904). (Reimpr. 1985), pp. 455-456.

${ }^{84}$ Tributum civium romanorum ex censu. Cfr.: HUMBERT, G., op. cit., p. 14. BLANCH NOUGUÉS, J. MANUEL, "Reflexiones en torno al interés jurídico del tributo y del derecho fiscal", en Hacia un Derecho Administrativo y Fiscal Romano. (Madrid, 2011), pp. 130 ss. CICCOTTI, E., "Lineamenti dell'evoluzione tributaria nel mondo antico", en I Tributi e L' Amministrazione Finanziaria nel Mondo Antico. (Padova, 1960), pp. 1-222, en especial, p. 82. = Vol.V della Biblioteca di Storia Economica. Dirett. Prof. V. Pareto. (Milano, 1921), pp. 7-220. NICOLET, C., Tributum. Recerches sur la fiscalité directe sous la republique romaine. (Bonn, 1976), pp. 27 ss. DI RENZO, op. cit., p. 131.

85 A partir de esta fecha hasta el año 43 a.C. no se volvió a exigir dicho tributo porque la victoria de la guerra contra Macedonia dejó repletas las arcas del erario. Cfr.: NICOLET, C., Censeurs et publicains. Économie et fiscalité dans la Rome antique. (s/l, 2000), pp. 99 y la bibliografía que allí se cita.

${ }^{86}$ Cicerón, ad fam. 12,30,4; Dion Casio 46,31,3-4. Cfr.: NICOLET, C., Tributum..., op. cit., p. 88.

${ }^{87}$ Sobre la determinación del impuesto, los requisitos de la professio censualis y los bienes comprendidos en el censo, cfr.: COLI, U., voz: census, en NNDI 3 (1959), p. 107. GUIRAUD, P., op. cit., pp. 440 ss. FUENTESECA, M., "Ius Publicum y pago de impuestos", en Direito Romano. Poder e Dereito. (Coimbra, 2013), pp. 861-862. En relación al carácter excepcional del tributo, cfr.: Tito Livio, 6,14,12; 6,12; 6,27; 6,32. Dionisio Halicarnaso, 5,20; Cicerón, De officiis, 2,21. Cfr.: HUMBERT, G., op. cit., pp. 14, en especial nota 2. FERNANDEZ DE BUJÁN, A., "Ius fiscale: Instrumentos...", op. cit., pp. 6 ss.

${ }^{88}$ DI RENZO, F., op. cit., pp. 127 ss. NICOLET, C., Tributum, op.cit., pp. 20 ss. LUZZATTO, G., “Tributum”, en NNDI 19, p. 852 .

${ }^{89}$ NICOLET, C., Tributum..., op. cit., pp. 5 ss.

90 Se aprecia, en este caso, la aplicación del principio de proporcionalidad y de capacidad económica, propio e informador del ordenamiento jurídico romano. Cfr.: FERNÁNDEZ DE BUJÁN, A., Derecho Público Romano. op. cit., p. 329. ID., "Ius fiscale: Principios...", op. cit., pp. 113 ss. ID., "Ius fiscale: Instrumentos de política financiera y principios informadores del sistema tributario romano", en Estudios Homenaje al Prof. Rodríguez Bereijo. (Madrid, 2000)). Desde otra perspectiva, cfr.: NICOLET, C., Rendre à César. Économie et Société dans la Rome Antique. (París, 1988), pp.196 ss.

${ }^{91}$ Cfr.: NICOLET, C., Tributum..., op. cit., pp. 22 ss.

92 Tito Livio, 28,39. DI RENZO, F., op. cit., p. 104 y pp. 127 ss. CICCOTTI, E., op. cit., pp. 82 ss, entre otros. 
la misma conllevaba una confusión entre lo que es verdaderamente un tributo y los préstamos públicos forzosos ${ }^{93}$.

El tratamiento de esta problemática es propia de otro foro. No obstante y, en relación con la época que se pretende contextualizar, parece más acorde la consideración de un tributo que gravara a los ciudadanos, sin ninguna obligación de retorno, ya que, como señala Cerami ${ }^{94}$, la devolución es propia de los préstamos y no de los tributos. En todo caso, en este momento, el Estado romano no tenía liquidez para devolución alguna, ya que carecía por completo de fondos para hacer frente a los gastos militares, y todo lo que pudiera recaudar sería para cubrir sus necesidades. La gravedad de las circunstancias hizo que, durante un tiempo, dicho tributo adquiriera prácticamente carácter anual, pero no por ello se convirtió en permanente, ni perdió su condición de imposición extraordinaria.

Se gravó también con impuestos a los ciudadanos excluidos del censo ordinario, a saber, las viudas y los sui iuris impúberes, de ambos sexos, los huérfanos, que figuraban en una lista especial a petición de sus tutores ${ }^{95}$. Ellos debían contribuir con el aes equestre y el aes hordearium destinados, respectivamente, a la adquisición de los caballos de las unidades de caballería de las legiones y a sufragar los gastos de forraje de los mismos ${ }^{96}$.

La situación se veía agravada por el hecho de que los latifundios ${ }^{97}$ estuvieran en manos de unos pocos y, además, que la tierra en Italia estuviera ordinariamente libre de impuestos.

Todas las ciudades de Italia tenían un régimen fiscal uniforme como consecuencia de la obtención de la ciudadanía, en cambio, no puede decirse lo mismo de las provincias, sobre las que recayeron las mayores cargas fiscales ${ }^{98}$.

Las provincias eran las que sostenían los gastos de funcionamiento de la República y estaban sometidas a una gran presión fiscal. Su régimen nunca fue homogéneo porque el mismo dependía de connotaciones diversas, generalmente de carácter político y, sobretodo, de la forma como se habían incorporado a Roma. En general, estaban sometidas a una presión fiscal muy fuerte, en especial las provincias de Oriente ${ }^{99}$.

En este sentido, se ha podido constatar que el ámbito de las provincias estaba sujeto a una imposición ordinaria, basada en la contribución fundaria que, según los casos, gravaba la porción de terreno cultivado a pagar en dinero -provincias stipendiariae- $\mathrm{y}$, en otros, lo que era objeto de imposición era el valor de los productos recolectados anualmente y se pagaba en especie -provincias decumae- ${ }^{100}$. Aunque se trata de una cuestión controvertida, se ha considerado que el tributum ex censu, a partir del año 167 a.C., una vez dejó de exigirse a los ciudadanos romanos,

${ }_{93}$ Di Renzo considera que se ha hecho una interpretación equivocada de las fuentes literarias que sirven de base a la opinión que defiende la naturaleza de préstamo, además afirma que los romanos no conocían aún la figura de este tipo de préstamo. Cfr.: DI RENZO, op. cit., pp. 128 y 132. Se pronuncia también en contra de la catalogación como de préstamo: CERAMI, P., Rec. Critic. de NICOLET, C., Tributum ..., op.cit., en IVRA 27 (1976), p. 162.

94 CERAMI, P., Ibid., p. 162.

95 A petición de sus tutores, los huérfanos de ambos sexos y las viudas se inscribirán en una lista especial del censo. Cfr.: Cicerón, De legibus, 3,3,7. Lex Iulia Municipalis 1,142-158 (=Tabula Heracleensis, 45 aC). GUIRAUD, P., op. cit., p. 446.

96 Cfr.: NICOLET, C., L’Ordre Équestre a l'Époque Républicaine. (312-43 av. J.-C.). T. I. (París, 1974), pp. 36 ss., y las fuentes que allí se citan. Y también, CICCOTTI, E., op. cit.,p. 85. DI RENZO, F., op. cit., p. 127 ss. En relación al aes hordearium y la discusión acerca de su origen, cfr.: PEPPE, L., Posizione giuridica e ruolo sociale della donna romana in età repubblicana. (Milano, 1984), pp. 138 ss. Y, en especial, las fuentes y la bibliografía de la nota 178. GABBA, E., "Esercito e fiscalità...", op. cit., pp. 24 ss.

${ }^{97}$ Cicerón, de leg. agr. 2,78. Varrón, re rústica, 1,2,3 y 1,2,6.

${ }^{98}$ DI RENZO, F., op. cit., pp. 107 ss. DI MARTINO, F., Storia della costituzione..., op. cit.Vol. IV. p. 280.

${ }^{99}$ DI RENZO, F., op. cit., pp. 152 ss.

${ }^{100}$ Gai 2,21. Cfr.: DI RENZO, F., op. cit., pp. 128 ss 
pasó a engrosar la imposición ordinaria de las provincias, de manera permanente, anual y con la finalidad de satisfacer necesidades militares ${ }^{101}$. Si dicho tributum hubiera adquirido carácter permanente no podría seguir denominándose así porque este nombre estaba reservado para indicar el gravamen extraordinario ${ }^{102}$. Sin embargo, sí pudo derivar en un impuesto directo que gravara el patrimonio de los habitantes provinciales.

Como ingreso del Estado, y con independencia de si se considera como una carga fiscal o un pago de un arrendamiento, existía el vectigal que era la renta impuesta a los detentadores del ager publicus ${ }^{103}$, entre los que podían encontrarse también ciudadanos romanos, cuya condición no les representaba ninguna exención fiscal ${ }^{104}$.

Al no ser suficiente la imposición directa para hacer frente a los enormes gastos militares, los triunviros recurrieron a la imposición indirecta, $\mathrm{y}$, en muchos casos, tuvieron presente planteamientos propios del derecho greco-helenístico ${ }^{105}$.

Con la imposición indirecta se gravaba la realización de determinados actos, y recaía sobre las cosas y no sobre las personas ${ }^{106}$. Se trataba de actos en los que de alguna forma el particular requería la intervención del Estado, dando lugar a la aplicación de impuestos indirectos como el portorium ${ }^{107}$. Se retomó la imposición de esta tasa con la que se gravaba el paso de los mercaderes y de sus mercancías por las fronteras del Estado, a la que estaba sujeto tanto el tráfico terrestre como el marítimo; de ahí las referencias al portorium maritimun y al portorium terrestre $e^{108}$, incluyendo dentro de este último las fronteras del territorio provincial. La doctrina no es unánime a la hora de determinar quién volvió a imponer dicho impuesto después de que fuera suprimido por el pretor Q.C. Metellus (año 60 a.C.), al menos para el territorio de Italia ${ }^{109}$. Algunos se decantan por César y otros lo atribuyen a los triunviros quienes se habrían encargado de reorganizarlo ${ }^{110}$. Sea como fuere, el hecho es que en la época que nos ocupa se exigía esta tasa.

Dion Casio y Apiano nos han dado a conocer que, entre los años 43 y 40 a.C., se establecieron por parte de los triunviros una serie de impuestos ${ }^{111}$. Se reinstauró la tasa que gravaba a

${ }^{101}$ En este sentido, LUZZATTO, G., op. cit., p. 852. Di Renzo destaca con razón que dicho tributo no podía ser el mismo que el tributo ex censu, porque el elemento significativo de éste último era su carácter extraordinario. DI RENZO, F., op. cit., p. 135 ss.

${ }^{102}$ Sobre los diversos sentidos que puede atribuirse a la palabra tributum, cfr.: LUZZATTO, G., op. cit., p. 852. NICOLET, C., Tributum, op. cit., p. 10. BLANCH NOUGUÉS, J. Ma ., op. cit., p. 131. FERNANDEZ DE BUJÁN, A., "Ius fiscale. Principios...”, op. cit., pp. 112 ss.

${ }^{103}$ NICOLET, C., Tributum..., op. cit., pp. 79 ss., entre otros.

${ }^{104}$ Sólo estaban sujetos a exención fiscal las tierras privadas que poseían los ciudadanos romanos en Italia. Cfr.: NICOLET, C., Rendre..., op. cit., p. 199.

${ }^{105}$ En este sentido, cfr.: SÁINZ DE BUJANDA, F., Ordenamiento financiero de la antigua Grecia y el período helenístico. (Madrid, 2013).

${ }^{106}$ CAGNAT, M. R., Étude historique sur les impôts indirects chez les romains jusqu'aux invasions des barbares. (Roma, 1966), p. 6.

${ }^{107}$ Impuesto que gravaba la importación de productos en puertos romanos. Fue un impuesto utilizado para corregir la inflación. Cfr.: FERNÁNDEZ DE BUJÁN, A., “Ius fiscali. Instrumentos...”, op. cit., p. 15. ZAMORA MANZANO, J. L., Algunos aspectos sobre el régimen fiscal aduanero en el derecho romano: reglamentación jurídica del "portorium", control de mercaderías y comiso por fraude fiscal. (Madrid, 2009). CAGNAT, M. R., op. cit., pp. 6 y ss., pp. 153 ss. NAQUET, H., Des impots indirects chez les romains sous la Republique et sous l'Empire. (Paris, 1875), pp. 6 ss. SPAGNVOlO VIGORITA, T., - MERCOGLIANO, F., op. cit.,p. 90. TORRENT, A., Voz: Portoria, en Diccionario, op. cit., p. 930.

${ }^{108}$ Lex Antonia de Termessibus. C.I.L. I, 204.1. 31 ss. Tito Livio, 38,44. Cfr.: CAGNAT, M. R., op. cit., p. 2 y, en especial nota 3 y p. 143 , nota 1 .

${ }^{109}$ CAGANT, M. R., op. cit., pp. 6 ss. NAQUET, H., op. cit., pp. 10 ss. CICCOTTI, E., op. cit., pp. 116 ss. DI RENZO, F., op. cit., pp. 118 ss.

${ }^{110}$ Ibid., p. 9.

${ }^{111}$ NICOLET, C., Tributum..., op. cit., pp. 88 ss. 
los esclavos, vicesima libertatis ${ }^{112}$, que obligaba a sus dueños a pagar por cada uno de ellos ${ }^{113}$, además de imponerles la obligación de dotar de esclavos a la flota ${ }^{114}$.

Se fijaron también contribuciones sobre los inmuebles tanto si estaban alquilados (se impuso una tasa equivalente al importe de un año de alquiler), como si estaban habitados por sus propietarios $^{115}$. A todo ello se unían los impuestos sobre las propiedades de los fundos tanto rústicos como urbanos ${ }^{116}$ y los impuestos sobre las ventas ${ }^{117}$, que, en estos momentos, sólo afectaban a las realizadas en pública subasta. A los senadores se les obligó pagar la reparación de los caminos $^{118}$. Se trató también de gravar con una tasa la herencia testamentaria, extremo sobre el que volveremos más adelante.

Con una finalidad política y a la vez recaudatoria, se adoptaron otro tipo de medidas distintas de las puramente fiscales. Basándose en las facultades que les otorgó la Lex Titia de rei publicae constituendae, los triunviros podían ordenar que se diera muerte a un ciudadano romano sin que hubiera mediado ningún proceso, ni ningún motivo legal ${ }^{119}$. Y, siguiendo lo que, unos años antes, había hecho $\mathrm{Sila}^{120}$, recurrieron a las proscripciones, que resultaron ser otra fuente recaudatoria.

Promulgaron un edicto triunviral de cuya existencia y contenido nos ha informado Apiano $^{121}$. En él, se legitimaba su actuación en el precedente silano, a la vez que se justificaba su promulgación en la necesidad de vengar el asesinato de César y de hacer desaparecer a los enemigos. Se hicieron constar, además, otros argumentos, alegaciones y frases laudatorias para Julio César y su política y, finalmente, afloró la verdadera realidad. Se dijo que las proscripciones y las asignaciones de tierras a los soldados constituían un medio para contentar al ejercito ${ }^{122}$.

Según los triunviros, los proscritos serían las personas que podían perjudicar la causa de la monarquía cesariana, incluyéndose en ellos los que hubieren violado el honor de César, entre los que figuraban, evidentemente sus asesinos ${ }^{123}$ y el propio Cicerón. En realidad, como describe Apiano, en la lista constaban todos aquellos que no apoyaban la legitimación y el poder del triunvirato y los enemigos personales de los triunviros ${ }^{124}$ y sus familias. Sobre todo se incidía en las personas de la nobilitas senatorial, simpatizantes de los tiranicidas. A todos ellos se les declaraba hostes rei publicae y, con ello, destinados a morir.

\footnotetext{
${ }^{112}$ SPAGNVOLO VIGORITA, T., - MERCOGLIANO, F., op. cit., p. 90

${ }^{113}$ Dion Casio 47,16, 3. Dicha tasa se había suprimido tres años antes.

${ }^{114}$ Dion Casio, 47,17,4; Apiano 5,67,282. Cfr.: NICOLET, C., Tributum..., op. cit., p. 89. Se trata de un impuesto distinto del de la la vicesima manumissionum o libertatis, que se estableció unos años más tarde por Augusto (año 7 dC). Apiano, 5,67 y 68. Dion Cassio, 47,17,4; 48,31,1. Cfr.: TORRENT, A., Voz: Vicesima manumissionum, op. cit., p. 1473. CAGNAT, M. R., op. cit., pp. 153 ss. y p. 227 y 232. CICOTTI, E., op. cit., pp. 116.

${ }^{115}$ Apiano, 4,5, Dion Cassio 47,14. Cfr.: NICOLET, C., Tributum..., op. cit., pp. 89 y 90.

${ }^{116}$ Apiano 4, 34; Dion Cassio 47,14,3. Cfr.: NICOLET, C., Tributum..., op. cit., p. 89.

${ }^{117}$ Apiano 4,5. Cfr.: NICOLET, C., Tributum..., op. cit., p. 90. Este gravamen era distinto de la centesima rerum venalium, referido a las ventas realizadas en subasta pública, que se estableció por Augusto. CAGNAT, M. R., op. cit., pp.113.

${ }^{118}$ Dion Casio, 46,31,3 y 47,17,4. Ibid.

${ }^{119}$ DE MARTINO, F., "Sugli aspetti giuridici...”, op. cit., pp. 520 ss.

${ }^{120}$ BECERRA OLIVA, G., op. cit., pp. 174 ss.

${ }^{121}$ Apiano 4,31-44.

${ }^{122}$ GABBA, E., "Miscelánea Triunviral", en Sociedad y politica en la Roma Republicana (siglos III-I a.C.). Ed. E. GabbaV. Laffi. (Pisa, 2000), pp. 289 ss, en especial, p. 290. Sobre las proscripciones puede consultarse también: CANFORA, L., "Proscrizioni e dissesto sociale nella repubblica romana", en Modelli étici, diritto e transformazioni sociali. Società romana e produzione schiavistica. Vol. III. Ed. A. Giardina y A. Schiavone. (Bari, 1981), pp. 207 ss. HINARD, F., Les proscriptions de la Rome Républicaine. (París, 1985), pp. 227 ss.

${ }^{123}$ Apiano 4,8,32-35. Cfr.: HINARD, F., op. cit., pp. 231 ss.

${ }^{124}$ Apiano 4, 5 y 6.
} 
En esta época, la declaración de hostes no se circunscribía a situaciones de guerra, ni se refería a extranjeros, sino que se aplicaba también a los ciudadanos romanos. Se trataba de una declaración que, en principio, podía realizar el Senado, a cuyo tenor, la persona afectada perdía sus derechos ${ }^{125}$, se le confiscaban sus bienes ${ }^{126}$ y podían ser ejecutados sumariamente ${ }^{127} \mathrm{y}$, una vez muertos, debía olvidárseles, damnatio memoriae ${ }^{128}$.

Tras el asesinato de César se elaboró una primera lista oficiosa ${ }^{129}$, a la que le siguió otra oficial, contenida en el edicto de proscriptiones ${ }^{130}$. A ésta le sucedieron otras listas cada vez más largas ${ }^{131}$. Con ello se perseguía la doble finalidad indicada anteriormente: deshacerse de sus enemigos, matándolos, amparados por la legalidad, y obtener un objetivo recaudatorio, procediéndose a la confiscación de todos sus bienes para su posterior venta en pública subasta; y, con lo obtenido, contribuir a hacer frente a los gastos del ejército y de las nuevas guerras ${ }^{132}$. En el propio edicto triunviral se hicieron constar los castigos para quienes ayudaran a los proscritos y las recompensas para los delatores ${ }^{133}$. Fue una auténtica masacre y se vivió una situación de terror $^{134}$.

Las propiedades de los proscritos ejecutados se organizaban en lotes y se ponían a la venta. Dadas las circunstancias, la concurrencia de compradores, en general, fue muy escasa, ya que unos temían que la adquisición les generara infortunio y otros no querían beneficiarse de la mala suerte de sus titulares. Sólo acudieron los más arrojados y lograron comprar a muy bajo precio $^{135}$.

Las ventas de los bienes de los proscritos resultaron insuficientes para hacer frente a los gastos que producían los enfrentamientos bélicos. Hubo que arbitrar nuevas medidas para obtener los recursos que se precisaban. Éstas se centraron en el patrimonio de las mujeres.

Apiano explica que los triunviros confeccionaron una lista pública de las mil cuatrocientas mujeres más ricas y promulgaron un edicto en el que se les exigía que realizaran una valoración de sus bienes, que serviría de base para que se pudiera fijar la aportación con la que cada una de ellas debería contribuir a los gastos bélicos. Todo ello bajo castigo a las que realizaran alguna ocultación de bienes o una estimación falsa, y recompensando a los delatores ${ }^{136}$, cualquiera que fuere su condición, libre o esclavo (año 42 a.C. $)^{137}$.

\footnotetext{
${ }^{125}$ Apiano, 1,60. Plutarco, Sulla 10.

${ }^{126}$ Apiano, 1,60; Cicerón, ad fam. 10,21,4.

${ }^{127}$ Cicerón, Cat. 4,10; Phil., 8,4,13.

${ }^{128}$ JAL, P., " $<$ Hostis publicus > dans la littérature latine de la fin de la République”, en REA 65 (1963), pp. 53 ss . DUPLÁ ANSUATEGUI, A., Videant Consules. Las medidas de excepción en la crisis de la república romana. (Zaragoza, 1990), pp. 155 ss.

${ }^{129}$ La realizó el cónsul Pedius en el año 43aC. (Apiano 4, 5 y 6). Cfr.: BETTI, E, op. cit., p. 504.

${ }^{130} \mathrm{El}$ edicto de proscriptines se publicó el 28 de noviembre del año 43 a.C. Cfr.: TORRENT, Voz: Proscriptio, en Diccionario..., op. cit., p. 1006.

${ }^{131}$ Apiano 4,7. En relación al texto y a la justificación de las listas de los proscritos, $c f r .:$ Apiano 4,8 y 9. Las primeras víctimas entre los proscritos, cfr.: Apiano 4,12. Cfr.: HINARD, F., op. cit., p. 231.

${ }^{132}$ BETTI, E., op. cit., p. 503 y, en especial, las fuentes que se citan en la nota 25. NICOLET, C., Censeurs..., op. cit., p. 88. La confiscación de bienes era una práctica habitual en los regímenes de la antigüedad, no sólo romanos, como fue el caso de Egipto bajo los Tolomeos. Cfr.: Inscripción de Rosette 1.19,20; Polibio, 21,19,1, todo ello citado por LUMBROSO, G., op. cit., p. 284.

${ }^{133}$ Sobre las recompensas, cfr.: LURASCHI, G., "Il < praemium> nell'esperienza giuridica romana", en Studi in onore di Arnaldo Biscardi. Vol. IV. (Milán, 1983), pp. 239 ss.

${ }^{134}$ Apiano 4,14.

${ }^{135}$ Apiano 4,31.

${ }^{136}$ Para los diferentes sentidos de la palabra y las diversas funciones del delator, $c f r .:$ GARCÍA CAMIÑAS, J., Delator: Una aproximación al estudio del delator en las fuentes romanas. (Santiago de Compostela, 1983).

${ }^{137}$ Apiano 4,32
} 
Las mujeres se sintieron muy ofendidas por dicha imposición y se opusieron activamente a la misma, lo cual las llevó a enfrentarse verbalmente a los triunviros logrando reducir el número de mujeres que debían presentar la valoración de sus bienes a cuatrocientas. Y se determinó también que, todos los hombres, tanto los ciudadanos, como los peregrinos y los libertos, sin exclusión de nadie, que poseyeran más de 100.000 dracmas deberían prestar de inmediato, bajo pena de multa y de recompensa a los delatores, una cincuentava parte de su patrimonio y contribuir a los gastos de la guerra con un año de sus rentas ${ }^{138}$.

\section{LA LEGISLACIÓN ORIENTADA A OBTENER UNA MAYOR EFICACIA EN LA SUCESIÓN TESTAMENTARIA Y LAS INICIATIVAS PARA GRAVAR LA SUCESIÓN MORTIS CAUSA}

La transformación de la economía y de la sociedad de la época favoreció la tendencia a considerar el patrimonio como un conjunto de bienes que podían ser objeto de tráfico comercial y que eran transmisibles hereditariamente. Se destacó el carácter económico de los elementos patrimoniales. La hereditas había adquirido carácter patrimonial: "hereditas est pecunia, quae morte alicuius ad quempiam pervenit iure nec ea aut legata testamento aut possessione retenta" 139 .

En este contexto, la herencia estaba en pleno proceso de configuración como una entidad incorporal jurídicamente relevante ${ }^{140}$. Se contempló como una unidad pecuniaria divisible en fracciones, el as hereditario ${ }^{141}$, y el heredero se convirtió en sucesor de los bienes del causante y no tan sólo en continuador del grupo familiar, como había sido hasta entonces.

El derecho de sucesiones estaba configurado de forma individualista ${ }^{142}$, teniendo profundamente arraigada la idea de la primacía de la sucesión testamentaria que se situaba por encima de la $a b$ intestato $^{143}$. Imperaba la libertad de testar que se vió consolidada por la configuración y por la aplicación del testamentum per aes et libram, y que sólo se vió limitada por la protección a los sui heredes (portio debita) ${ }^{144}$, amparada por la querella inofficiosi testamenti ${ }^{145}$-que podría utilizarse en los casos en los que el testador hubiera actuado contra officium pietatis- y por algunas leyes limitadoras de los legados. No falta quien ha querido interpretar este medio de protección como una medida para preservar los grandes patrimonios, además de asegurar la efectividad del testamento ${ }^{146}$.

\footnotetext{
${ }^{138}$ Apiano, 4,34; Dion Cassio, 48,6,4-5. Cfr.: HEICHELHEIM, F.M., Historia Social y Económica de Roma. Trad. esp. (Madrid, 1982), pp. 78 ss. ORTUÑO PÉREZ, Ma. E., "Hortensia. Su discurso contra la imposición fiscal femenina", en AA.VV., Mujeres en tiempos de Augusto. Realidad social e imposición legal. (En prensa en ed. Dykinson, Colección Monografías de Derecho Romano).

${ }^{139}$ Cicerón, Top., 6,29.

${ }^{140}$ D. 5,3,50 pr (Pap., lib. 6, Quaest).

${ }^{141}$ BIONDI, B., Sucesión testamentaria y donación. Trad. esp. (Barcelona, 1960), p. 226, y las fuentes y la bibliografia que allí se citan. FUENTESECA, P., Derecho Privado Romano..., op. cit., p. 347. SCHULZ, Derecho Romano Clásico. Trad. esp. (Barcelona, 1960), pp. 198 ss. KASER, M., Das Römische Privatrecht. Erster Abschnitt. (München, 1975), pp. 320 ss. JÖRS, P., - KUNKEL, W., Derecho Privado Romano. Trad. esp. (Madrid, 1985), p.435 ss., entre otros.

${ }^{142}$ SCHULZ, F., Principios del Derecho Romano. (Madrid, 1990), pp. 178 ss.

${ }^{143}$ VOCI, P., Diritto ereditario. Vol. I. (Milano, 1960).

${ }^{144}$ SCHULZ, F., op. cit., p. 198, entre otros.

${ }^{145}$ Ibid. p. 263. KASER, M., op. cit., pp. 515 ss.

${ }^{146}$ KASER, M., op. cit., p. 301.
} 
En este sentido, ha de mencionarse la Lex Falcidia de Legatis, propuesta por el Tribuno Publius Falcidius en el año 40 a.C. ${ }^{147}$, en la que, en su primer capítulo, dejaba sin aplicación las limitaciones a la capacidad de legar impuestas a los ciudadanos por las leyes precedentes, la Lex Furia (s/d?) $)^{148}$ y la Lex Voconia de Mulierum Hereditatibus (año 169 a.C.) ${ }^{149}$. Y, en el segundo capítulo, establecía que el causante no podía legar más que las tres cuartas partes de la herencia, porque el cuarto restante -la cuarta falcidia- debía reservarse en todo caso al heredero testamentario $^{150}$. Los legados que excedieran de dicha disposición, se reducirían proporcionalmente ${ }^{151}$.

Se trata de una lex publica rogata ${ }^{152}$ que forma parte del escaso elenco de leyes reguladoras de materias relativas al derecho privado ${ }^{153}$, promulgadas desde inicios de la República y que cumple las mismas connotaciones que las demás ${ }^{154}$. El hecho de regular una materia de derecho privado no es óbice para que pueda advertirse en la misma un trasfondo basado en el interés público, ${ }^{155}$ que puede encontrarse en las circunstancias del momento. En este sentido, la relación de clientelismo que imperaba tanto en el ámbito civil como en el militar, a la que nos hemos referido anteriormente, hacía proclive la utilización de los legados, con lo que podría producirse una excesiva reducción del caudal hereditario. Esta pudo ser una de las causas que motivaron la promulgación de la Lex Falcidia de Legatis, porque al imponer una limitación en la capacidad de disposición del causante en aras del favor testamenti, se evitaba que la herencia se convirtiera en damnosa para el heredero o que para éste fuera un simple nomen iuris.

${ }^{147}$ Apiano 5,67 y Dion Casio 47,31,33;34. Cfr.: NICOLET, C., op. cit., p. 95, en especial nota 142. MÜNZER, en $P W$ VI, 1909, col. 1969 nr.3. BRUNS, p.110 nr. 19. ROTONDI, G., op. cit., p. 438. STEINWENTER, en PW. XII, 1925, col. 2346. BERGER, Enc. Dict. p. 552. TIBILETTI, G., "Voz: Lex Falcidia de Legatis", en DE RUGGIERO, E., Dizionario Epigrafico di Antichità Romane. , IV. Fasc.2, (Roma, 1956), p.731-732, entre otros.

${ }^{148}$ Gai 2,225: ... Lex Furia, qua exceptis personis quibusdam ceteris plus mille assibus legatorum nomine mortisue causa capere permissum non est.

${ }^{149}$ Gai 2,226: ... Lex Voconia, qua cautum est, ne cui plus legatorum nomine mortisue causa capere liceret, quam heredes caperent. Cfr.: ORTUÑO PÉREZ, M. E., "Una limitación de la capacidad patrimonial de la mujer en el ámbito sucesorio: La Lex Voconia”, en Mulier. Algunas Historias e Instituciones de Derecho Romano. Ed. R. Rodríguez López. $\mathrm{M}^{\mathrm{a}} \mathrm{J}$. Bravo Bosch (Madrid, 2014) y la bibliografia que allí se cita. Un sector doctrinal ha vinculado el establecimiento de la vicesima hereditatium a la Lex Voconia. Cfr.: CAGNAT, M. H., op. cit., pp. 179 ss. CICOTTI, E., op. cit., p. 87 , notas 1 y 2 , en donde recoge la problemática doctrinal al respecto.

${ }^{150}$ Gai 2,227: ...Lex Falcidia, qua cautum est, ne plus ei legare liceat quam dodrantem: itaque necesse est, ut heres quartam partem hereditatis habeat: et hoc nunc iure utimur.Y también, D.35,2,1 pr (Paul., lib. Sing. ad legem Falcidia) y Dion Casio, 48,33. Cfr.: ROTONDI, G., op. cit., p. 438. BARBIERI, G., Voz: Lex, en DE RUGGIERO, E., Dizionario..., op. cit.. Vol. IV, Fasc. 22, pp. 731-732. BRUNS, K.G., FIRA, Parts prior. (Tübingen, 1909-1969), n. 19 , p. 110. BUCKLAND, W. W., A textbook of Roman Law. (Cambridge, 1921) p. 338. JOLOWICZ, H. F., Historical introduction to the study of Roman Law. (Cambridge, 1932), pp. 25 ss. RUDORFF, A. F., Römische Rechtsgeschichte. (Leipzig, 1857). BONIFACIO, F., Ricerche sulla "Lex Falcidia de Legatis". (Napoles, 1948); ID., "In tema di Lex Falcidia", en IVRA, 3 (1952), pp. 229 ss. ORTUÑO PEREZ, Ma. E., "A new perspective on the limitation of legacies. (Lex Falcidia de Legatis), en SDHI 80 (2014), pp. 411 ss.

${ }^{151}$ La disposición de la Lex Falcidia se extendió más tarde, sobre el año 77 d.C., a los fideicomisos a traves del Senatusconsultum Pegasianum de Fideicommissis.

${ }^{152}$ Gellio, 10,20,2: generale iussum populi, rogante magistratu. Pudo publicarse una lex rogata pese a la situación excepcional que se vevía porque los órganos constitucionales republicanos continuaron funcionando aunque bajo el control estricto de los triunviros. Cfr.: LAFFI, V., "Poderes triunvirales...", op. cit., pp. 313 ss.

${ }^{153}$ En el período concreto del segundo triunvirato sólo se prumulgaron dos leyes de derecho privado: la Lex Falcidia de Legatis y la Lex Iulia et Titia (año 31 a.C.), relativa a la tutela impuberum.

${ }^{154}$ TALAMANCA, M. (Coord.), Lineamenti..., op. cit., pp. 254 ss. ROTONDI, G., "Osservazioni sulla legislazione comiziale romana di diritto privato", en Scritti. Vol I. (Milano, 1910), pp. 4 ss. Sobre la intervención normativa del Senado en época republicana, $c f r$.: CRIFÒ. G., "Attività normativa del Senato in età repubblicana", en BIDR 10 (1968), $3^{\mathrm{a}}$ serie, pp. 41 ss.

${ }^{155}$ Ibid., p.18. SERRAO, F., Voz: Legge (Dir. Rom.), en ED 23 (1973), pp. 815 ss. Schulz hace referencia a los supuestos de derecho privado en los que utiliza la ley y, entre ellos, alude a aquellos en los que las normas son muy precisas, como es el caso de la Lex Falcidia. Cfr.: SCHULZ, F., Principios..., op. cit., pp. 30 ss. FUENTESECA, P., Historia..., pp. 202 ss. ORTUÑO PEREZ, Ma E., “A new...”, op. cit., pp. 411 ss. 
La protección de los herederos y la voluntad de que los testamentos llegaran a tener eficacia iba acompañada de la intención de los triunviros de gravar con una tasa la transmisión patrimonial que recibiría el sucesor como consecuencia del fallecimiento del causante. Todo ello estaba orquestado en el marco de la política financiera que pretendía corregir la inflación con la imposición indirecta.

Este fue el transfondo de la ley y es lo que explica que los triunviros se preocuparan de este aspecto del derecho privado en una situación en la que el estado de guerra civil era la constante. El ámbito sucesorio contemplado por los triunviros era más amplio. Se tuvieron en consideración a los militares. En coherencia con la política favorecedora que se había seguido, se arbitró una medida para garantizar la posibilidad de que pudieran transmitir mortis causa el patrimonio adquirido. Antes de este segundo triunvirato, César reconoció por primera vez, y a modo de privilegio personal, la eficacia de las disposiciones de última voluntad realizadas por los militares. En aquella época se hablaba del testamento in procinctu como un recuerdo histórico $^{156}$, quizá porque había quedado muy lejos su carácter público-religioso y el tener que otorgarse tras los auspicios del general y ante el populus centuriatus. De la misma manera también era lejana la primigenia configuración del ejército, ya que el que existía en la época del dictador obedecía al modelo surgido como consecuencia de la reforma realizada por Mario y, como se ha visto, se trataba de un ejército profesional compuesto, en su gran parte, por campesinos pobres, proletariado urbano y por mercenarios de cualquier procedencia. Los militares no libraban las batallas ni las guerras como antaño, por Roma, sino que su actuación se debía a las compensaciones que recibirían después de las mismas y que les permitían obtener un patrimonio que de otra forma no habrían tenido posibilidad de conseguir.

En este contexto, Julio César, en su política favorecedora del ejército y de la sucesión testamentaria otorgó, como un privilegio temporal -temporalis concessio- la posibilidad al testador de poder expresar su voluntad en cualquier momento y sin ajustarse a formalidad alguna, atribuyéndole a este acto valor jurídico pleno. Y consiguientemente, a la muerte del testador, se debía proceder a la apertura de la sucesión testamentaria ${ }^{157}$. La eficacia de tal testamento quedaba así garantizada, en un momento en el que los militares, de no ser por dicha concesión, no habrían tenido la posibilidad de poder testar, porque la realidad bélica que se vivía hacía casi imposible que estuvieran en condiciones de poder otorgar un testamento ordinario válido. A lo que hay que añadir el posible y más que probable desconocimiento del derecho romano por parte de los soldados que hubieran accedido recientemente a la ciudadanía romana ${ }^{158}$.

\footnotetext{
${ }^{156}$ Cicerón, de nat. deor. 2,3,9.

${ }^{157}$ Ulpiano en su comentario al edicto atribuyó a César el primer testamento militar : Militibus liberam testamenti factionem primus quidem divus Iulius Caesar concessit: se dea concessio temporalis erat [...]. Cfr.: D.29,1,1 pr. (Ulp., 40 ad ed). Se trató de una concesión temporal, ya que, como figura autónoma, hubo que esperar hasta la dinastía de los Flavios para que el emperador Tito lo creara como tal (81-96 dC). Partimos de la autenticidad del fragmento aunque hay una parte de la doctrina que considera que el texto de Ulpiano esta interpolado en relación a la mención a Julio César. En este sentido, Cfr.: ARANGIO RUIZ, V., "L'origine dei testamentum militis", en BIDR (1906), pp. 157 ss. GUARINO, A., "Sull'origine del testamento dei militari nel diritto romano", en RIL 72 (1938-39), pp. 355 ss. El status questionis sobre la materia lo recoge SCHERILLO, G., "D. 1,4,3 (Giavoleno, 1.13 EP) e il testamento militare", en Studi Volterra. Vol. III (Milano, 1971), p. 616, nota 9. También aluden a esta problemática, cfr.: HERNANDEZ GIL, A., El testamento militar. (Madrid, 1996) y la bibliografía que allí se cita. BRAGE CAMAZANO,J., “El Testamentum militis”, en Revista Jurídica del Notariado, (abril-junio, 2007), pp. 43 ss. GOMEZ ROYO, E., “El testamento militar en las fuentes jurídicas romanas y griegas", en Estudios de Derecho Romano e Historia del Derecho Comparado. Estudios interdisciplinares en homenaje a Ferrán Valls i Taberner. (Madrid, 1991), p. 5351 ss. MARLASCA MARTÍNEZ, O., "Estudio histórico del testamento militar", en RGDR 18 (2012), pp. 1-34, entre otros. Sobre la concesión temporal, cfr.: JOHNSON, J. P., “A note on Caesar's military Hill. Why was it a concessio temporalis?", en Labeo 26 (1989), pp. 335 ss. TALAMANCA, M., Istituzioni di Diritto Romano (Milano, 1990), pp. 64 ss., entre otros.

${ }^{158}$ En este sentido, PUGLIESE,G., Istituzioni di Diritto Romano. (Torino, 1991), p. 680 ss.
} 
Como es obvio, en todas las medidas adoptadas en favor testamenti se encontraba implicita la finalidad recaudatoria.

\section{LA IMPOSICIÓN DE UNA TASA QUE EN ROMA TUVO QUE ESPERAR: LA VICESIMA HEREDITATIUM}

Las iniciativas jurídicas descritas en relación al ámbito sucesorio pretendían completarse con la imposición de un gravamen sobre la transmisión patrimonial de los bienes hereditarios, lo cual debía interpretarse como una de las medidas previstas para la corrección de la inflación y para superar el déficit.

Para ello se fijó el punto de mira en el derecho extranjero, partiendo de la idea que el propio Julio César manifestó: "Nuestros mayores no eran tan soberbios como para no querer imitar las instituciones extranjeras. Lo que han encontrado útil, tanto en los amigos como en los enemigos lo han adoptado también en la patria con la mayor diligencia; han preferido imitar a los hombres competentes mejor que envidiarles" ${ }^{159}$.

La Roma necesitada de fondos tuvo en consideración la antigüa fiscalidad de Egipto ${ }^{160}$. Las relaciones entre una y otro venían de $\operatorname{lejos}^{161}$. Se basaron en acuerdos de amistad y en cesiones de soberanía por parte de algunos reyes Lágidas quienes, aplicando la concepción patrimonial del Estado propia de las monarquías orientales, transmitieron su soberanía por vía testamentaria en favor del pueblo romano ${ }^{162}$. Ni estos hechos ni tampoco los intentos de anexión realizados por Roma ${ }^{163}$, le hicieron perder por completo su autonomía, hasta que Augusto logró convertirlo en provincia romana.

Roma tenía presente a Egipto. No sólo cuando contó con su ayuda en el ámbito bélico, como en el caso del apoyo naval prestado por el rey Ptolomeo Soter II a Sila en la guerra de Mitridate, sino que su anexión estuvo siempre en el punto de mira romano por tratarse de un lugar estratégico, por su peculiar economía y porque podía ser una posible salida de la grave crisis financiera romana ${ }^{164}$.

Egipto también se apoyó en Roma en muchas ocasiones, sin que llegara a ser, de momento, una provincia romana sino que sólo era un reino amigo de Roma ${ }^{165}$. Los Lágidas mantenían la aplicación de su propia legislación y planearon la administración del reino como si éste fuera un patrimonio privado y así lo gestionaron. La economía del reino se confundía con la

${ }^{159}$ César, Catil., 51, 37-38: neque (maioribus nostris) superbia obstabat quo minu. Aliena Instituta, si modo proba erant, imitarentur... quod ubique apud socios aut hostis idoneum videbatur, cum summo studio domi exsequebantur: imitari Quam invidere bonis malebant. Cfr.: SCHULZ, F., Principios..., op. cit., p. 149.

${ }^{160}$ Apiano 2,154, afirma que Egipto fue la escuela de César. Cfr.: LUMBROSO, op. cit., p. 308.

${ }^{161}$ Un primer contacto partió de Egipto hacia Roma. Y tuvo lugar a requerimiento de Ptolomeo II, Filadelfo (308-246 a.C.), que envió una embajada a Roma con presentes y con el ofrecimiento de amistad y de alianza (año 273 a.C.). Más tarde, se sucedieron diferentes tratados de amistad y de protección e intervenciones de Roma en la política egipcia. Sobre el particular, cfr.: LUZZATTO, G. I., Appunti di papirologia Giuridica. (Bologna,s/d), pp. 91 ss. Y también, CIACERI, E., Processi Politici e Relazioni Internazionali. (Roma, 1918), pp. 40 ss.

${ }^{162}$ La relación de los diferentes testamentos reales egipcios en favor del pueblo romano, puede consultarse en. LUZZATTO, G. I., op. cit., pp. 97 ss.

${ }^{163}$ Por ejemplo, la Rogatio de Aegypto, que fue una propuesta de plebiscito por el que César, después de ejercer como edil, debía convertir a Egipto en provincia romana, aprovechando que entonces gobernaba Ptolomeo Auletés, en aquellos momentos no reconocido por Roma. Da cuenta de ello Cicerón, de l. arg. 2,17,44. Cfr.: ROTONDI, G., op. cit.,p. 377.

${ }^{164}$ PIRENNE, J., Historia del antiguo Egipto. Vol. III. Trad. esp. (Barcelona, 1983), p. 413.

${ }^{165}$ PRÉAUX, C., "La singularité de l'Egypte dans le monde greco-romaine”, en Chron. Egipt. 25 (1950), pp. 110 ss. TORRENT, A., La Constitutio Antoniniana..., op. cit., pp. 97 ss. y la bibliografía que allí se cita. 
administración regia ${ }^{166}$. Y se caracterizaba por su planificación y por su dirigismo. Era totalmente centralizada y giraba en torno al rey y a su primer ministro, el diocete, que era ministro de finanzas, cuyas competencias afectaban a la totalidad de los asuntos del Estado.

En Egipto, la organización financiera y, en concreto, los impuestos eran un medio para sostener al rey y a la estructura administrativa del Estado ${ }^{167}$. Como afirma Rostovtzeff ${ }^{168}$, la organización económica estaba planteada para hacer al rey más rico y poderoso. El rey se identificaba con el Estado. Y la organización del Estado era enormemente burocrática y estaba sometida al control real, ejercido a través de los altos órganos del que podría denominarse gobierno cen$\operatorname{tral}^{169}$.

La tributación estaba planteada desde un punto de vista práctico y en función de la configuración propia de Egipto. Se pretendía la obtención del máximo rendimiento fiscal y, por ello, la imposición se hacía extensiva a cualquier actividad económica, lo que generó tal magnitud de tributos que, resulta muy compleja su consideración pormenorizada. En la época de los Ptolomeos la imposición fiscal fue mucho más fuerte que en los períodos precedentes ${ }^{170}$. La imposición se basaba en una imposición directa, cuya figura primordial era la imposición fundaria ${ }^{171}$, si bien también existían impuestos sobre las personas. Todo lo cual no fue óbice para que se gravaran mediante la imposición indirecta gran parte de los actos que realizaban los ciudadanos, como es el caso de las transmisiones patrimoniales que se sometieron a imposición y a inscripción. Primero se gravaron las transmisiones generadas por las ventas, después las hipotecas, y, por último, se gravaron también las herencias.

En relación a la tributación de las herencias, se conoce de su existencia por unas líneas del primer Papiro de Turín ${ }^{172}$, en las que se relata una reclamación judicial formulada el 11 de diciembre de 117 a.C., en tiempos del rey Ptolomeo VIII Evergetes II, apodado el Fiscón ${ }^{173}$. La causa se conoce como el proceso de Hermias ${ }^{174}$. Al parecer, Hermias fue un oficial de la ciudad

${ }^{166}$ PRÉAUX,C., L’Économie royale des Lagides. (Bruselas, 1939), p. 427. WILL, E., -MOSSÉ, C., - GOUKOWSKY, P., El mundo griego y el oriente. T. II. El siglo IV y la época helenística. Trad. esp. (Madrid, 1998), p. 420 y 467. HUSSON, G., - VALBELLE, D., Instituciones de Egipto. Trad. esp. (Madrid, 1998), pp. 290 ss. ROSTOVTZEFF, Historia social y económica del mundo helenístico. Vol.I, Trad. esp. (Madrid, 1967), pp. 260 ss. LÊVÊQUE, P., El mundo helenístico. Trad. esp. (Barcelona, 2005), pp. 57 ss. SHIPLEY, G., El mundo griego después de Alejandro (323-30 a.C.). Trad. esp. (Barcelona, 2001), pp. 248 ss.

${ }^{167}$ MENU, B., Recherches sur l'histoire juridique, économique et sociale de l'ancienne Égypte. II (París, 1998), pp. 14 ss. = "Principes fondamentaux du droit égyptien", en CdE 70 (1996), pp. 99 ss. BEVAN, E., Histoire des Lagides. 323-30av. J.C. (Paris, 1934), pp.174 ss. PIRENNE, J., op. cit., Vol. III, pp. 383 ss. WILL, E., MOSSÉ, C., GOUKOWSKY, P., El mundo griego y el Oriente. T. II. El siglo IV y la época helenística. Trad. esp. (Madrid, 1998), pp. 420 ss. Y también, SEIDL, E., Ptolemäische Rechtsgeschichte. (Hamburg, 1962).

${ }^{168}$ ROSTOVTZEFF, M., op.cit., p. 317.

${ }^{169}$ Entre otros, cfr.: PIRENNE, J., op. cit., Vol. III, pp. 383 ss. No se conoce la fecha en la que se creó la tasa que grava la herencia, pero se cree que procede del período de la dinastía de los Lágidas . Cfr.: LUMBROSO, G., op.cit., p.307.

${ }^{170}$ SHIPLEY, G., op. cit., pp. 253 ss. Una relación de los impuestos Cfr.: WILCKEN, U., Griechische Ostraka. Vol. I. (Amsterdam, 1970), p. 199. ID., Urk. Der Ptolomäerzeit. T.II, pp. 45-46. A ellos se debe también la introducción del arrendamiento de los impuestos. Cfr.: PIRENNE, J., op. cit., Vol. III, pp. 384 ss.

${ }^{171}$ SHIPLEY, G., op. cit., pp. 248 ss y, en especial, pp. 253 ss. HUSSON, G.,- VALBELLE, D., op.cit., pp. 289 ss. A partir de la $3^{\mathrm{a}}$ dinastia se transformó la propiedad egipcia y se concentró en manos de unos pocos. La mayoría del territorio era propiedad del rey, aunque también existían tierras que eran propiedad de los templos y de los colegios sacerdotales. Este régimen continuó bajo los Lágidas. Cfr.: PIRENNE, J., op. cit., Vol. III, p. 267 ss. VOLTERRA, E., Diritto Romano e Diritto orientali. (Bologna, 1937), pp. 142 ss., y la bibliografía allí citada.

${ }^{172}$ Pap. Tur. 1, p. 7, 1.10-13. P. Tor (Mitteis, L., Chrest.31) col.X 1 y ss. P. Par 15 (UPZ II 161) Cfr.: WILCHEN, Ost., I, IV,140.

${ }^{173}$ La situación política egipcia de este momento puede consultarse en WILL, E., Histoire Politique du Monde Hellénistique (323-30av.J.C.). T. II. Des avènements d'antiochos III et de Philippe V a la fin des Lagides. (Nancy, 1967), pp. 366 ss.

${ }^{174}$ PESTMAN, P. W., The archive of the Theban Choachytes (Second Century B.C.). (Leuven, 1993), pp. 163-169. 
de Omboi ${ }^{175}$, el cual citó ante la justicia a un grupo de choachytes -que eran una casta sacerdotal egipcia encargada de la liturgia y de la lectura de las fórmulas en los embalsamamientos de los difuntos- acusándolos de haber ocupado una casa que había heredado de un antepasado, ubicada en el distrito sur de Dióspolis ${ }^{176}$. Se trata de la ciudad de Dióspolis Magna, llamada por los griegos, Tebas ${ }^{177}$. Al parecer, la casa estaba situada cerca de un río y al lado de un canal, por tanto pudo estar provista de tierras cultivables ${ }^{178}$. No se tiene constancia de si la tierra era katöke, es decir, tierras cedidas a los soldados por los reyes Lágidas ${ }^{179}$, o se trataba de tierra privada, $G e$ idioktetos $^{180}$. Lo que sí se conoce es que la casa había pertenecido a un antepasado de Hermias, un soldado griego que hacía el año 200 a.C., durante las insurrecciones indígenas, había abandonado Tebas ${ }^{181}$. Tras el abandono, la casa fue ocupada por personas desconocidas. Unos años más tarde, tres familias de choachytes la compraron y hacía el año 120 a.C., Hermias intentó reiteradamente expulsarlos y recuperar la casa ${ }^{182}$.

Todo apunta que el caso se sometió a la jurisdicción griega (dikasteria) ${ }^{183}$, que dirimía las controversias sobre el derecho de propiedad decidiendo cuál de los contendientes tenía mejor derecho $^{184}$. De ahí que los argumentos de los representantes de las partes se dirigieran a probar dicho extremo ${ }^{185}$.

${ }^{175}$ CALDERINI, A., Dizionario dei nomi geografici e topografici dell'Egitto greco-romano. (Milan, 1966), pp. $385-386$. WORP, K.A. - DIJKSTRA, J. H. F., "The administrative position of Omboi and Syene in Late Antiquity", en Zeitscnift für Papyrologie und Epigrafik (Bonn, 2006), Vol. 155, pp. 183-187.

${ }^{176}$ HEILPORN, P., Thèbes et ses taxes.Recherches sur la fiscalité en Égypte romaine. (Ostraca de Strasbourg II ). (Paris, 2009), p. 37 y en especial notas 29 y 30.

${ }^{177}$ AA. VV., Historia de Egipto. MANETÓN. Ed. de J. Jiménez Fernández y A. Jiménez Serrano. (Madrid, 2008). CORONA BUSTAMANTE, F., Curso completo de Geografía universal antigua y moderna. (París, 1858) y ed. Pontificia Università Laterenense, 1961.

${ }^{178}$ Sobre la ubicación de la casa, PESTMAN, P. W., P. Choach. Survey, p. 385-400, citado por HEILPORN, P., op. cit., p. 37, notas 34 y 35 .

${ }^{179}$ Las tierras katöke eran tierras cedidas en posesión a los soldados , la cual debería convertise con el tiempo en propiedad. Posiblemente estaban sujetas al pago de algún canon al Estado. Cfr.: TELL, G. A., "El registro de la propiedad en Egipto en la época romana", en Revista Crítica de Derecho Inmobiliario 602 (1991), p. 181. Artículo basado en la obra de: EGER, O., Zum Ágyptischen Grund buchwesen in römischer Zeit. (Leipzig- Berlin, 1909).

${ }^{180}$ TELL, G. A., op. cit., p. 181.

${ }^{181}$ P. Varsovie 148.288, en PESTMAN, P. W., The Archive of the Theban Choachytes. Vol. I. (Leiden, 1977), p. 100.

${ }^{182}$ Ibid., p. 102.

${ }^{183}$ En este momento, existía aún la duplicidad de jurisdicciones; además de la griega, había la egipcia (laokritai) que hasta que no se produjo la intervención de Roma seguían caminos autónomos. Sin perjuicio de que, en relación a la aplicabilidad del derecho, existía la tendencia de abandonar el principio de personalidad para que llegara a primar el principio de territorialidad. La situación descrita era una consecuencia del tipo de Estado creado por la dinastía ptolomaica que, para legitimar y para apoyar su gobierno, incorporó a la legislación y costumbres egipcias provenientes de las épocas de los faraones, el centralismo del Estado y, por ende, el de que la Administración viniese abocada a la aplicación del principio de territorialidad. Cfr.: WILL, E. -MOSSÉ, C. - GOUKOWSKY, P., op. cit., p. 384, nota 444. Sobre la pluralidad de derechos en el Egipto de los Lágidas, cfr.: WOLFF, H. J., "Plurality of Laws in Ptolemaie Egypt", en RIDA 7 (1960), pp. 191-223. ID., "Diritto greco-Diritto Tolemaico", en DIKE 16 (2013), pp. 121 ss. Sobre el derecho del Egipto, puede consultarse también: TAUBENSCHLAG, R., The Law of Greco-Roman Egypt in the Light of the Papiri: 323 BC.-640 AD. (Warszawa, 1955). WILCKEN, U. - MITTEIS, L., Grundzïge und Chrestomathic der PapyrusKunde (Teubner, 1912) y (Hildesheim, 1963).

${ }^{184}$ Ha realizado una reconstrucción de la organización judicial: WOLFF, H. J., Das Justizwesen der Ptolemäer. (München, 1962). ID., "The origin of Judicial Litigation Among the Greeks", en Traditio. Studies in Ancient and Medieval History, Thought and Religion.. Vol. IV (New York, 1946), p. 366. ID., "Diritto...", op. cit., pp. 119 ss. MODRZEJEWSKI, J., "Réflexions sur le droit ptolemaïque", en IURA 15 (1964), pp. 53 ss. En relación al mantenimiento del derecho griego y del egipcio, $c f r .:$ PRÉAUX, C., "Sur la reception des droits dans L'Egypte greco-romaine", en RIDA 5 (1950), pp. 352 ss.

${ }^{185}$ Algún autor ha referido la contienda de Hermias, más que como un proceso, como una reclamación administrativa. En éste sentido, HEILPORN, P., op. cit., p. 38. 
La base jurídica de la reclamación pudo apoyarse en unos prostagramas, de Ptolomeo Evergete II, que, al igual que algunos de sus predecesores, cuya referencia figura en las Ordenanzas Ptolomaicas, reconocían un derecho de propiedad a los posesores actuales de los inmuebles y les garantizaban los títulos de adquisición ${ }^{186}$. En base a ello, la contienda iniciada por Hermias se basó sobre la legitimación de la ocupación del inmueble ${ }^{187}$.

En el proceso intervinieron los respectivos abogados, Philocles, por la parte de Hermias, y Dinon, por la parte de los sacerdotes. Y este último se opuso a la reclamación formulada demostrando que la casa pertenecía realmente a sus clientes apoyando sus argumentos, entre otros extremos, en que si Hermias hubiera recibido verdaderamente la propiedad de la casa de sus ascendientes, tendría que haberla inscrito en los registros públicos hereditarios y tendría que haber pagado la tasa fijada, ya que, de lo contrario, se le habría impuesto una multa y se habría anulado la gestión realizada por la Administración ${ }^{188}$.

Se alude a la inscripción de la transmisión en el registro de herencias ${ }^{189}$, lo cual constata la existencia de un control público sobre la legitimación de la disposición mortis causa ${ }^{190}$ y de la transmisión que a la vez se utilizaría desde la perspectiva fiscal ${ }^{191}$. Dicha inscripción se realizaba previa declaración de los herederos que se hacia constar en un documento -apografe-, el cual se consignaba en el Registro de cambios o transmisiones de derechos ${ }^{192}$.

La exigencia de la inscripción provenía del derecho greco-egipcio que consideraba al documento escrito como un elemento probatorio fundamental ${ }^{193}$ y a la inscripción en el registro como un medio eficaz de control de las transmisiones que facilitaba la imposición y la exacción tributaria ${ }^{194}$.

\footnotetext{
${ }^{186}$ P. Par. 15 (= UPZ 161), 11. 57-59 (26 junio 119) y P.Tor. I (= M.Chrest.31 = UPZ 162), col. V 11. 21-24. Todo ello citado en: LENGER, M. T., Corpus des Ordenances des Ptolémées. Reimpr. De l'édition princeps (1964) corrigée et mis à jour. (Bruxelles, 1980), p.253, All.59. En relación a otros aspectos del juicio pueden consultarse también All. 70 y All. 74, p. 256 y 257 respectivamente. Estas ordenanzas y unos postragramas del mismo rey Evergete II obedecen a la intención de solucionar las situaciones equívocas creadas como consecuencia de las confiscaciones de tierras realizadas durante las guerras civiles del siglo II. Cfr.: Ibid. All. 59, p.253. En relación a la facultad legislativa de los reyes ptolemaicos y a la obligatoriedad de sus normas, $c f r .:$ LENGER, M. T., "Les Ptolémées Législateurs", en RIDA 50 (1964), pp. 1 ss.

${ }^{187}$ Wolff considera que Hermias pretende la recuperación de la posesión de la casa más que el reconocimiento del título de propiedad. Cfr.: WOLFF, H. J., "The origin of judicial litigation Among the greeks", en Traditio. Studies in ancient and medieval history, thought and religion. Vol. IV. (New York,1946), p.368, nota 113. Y cita en el mismo sentido a SCHÖNBAUER, E., Beiträge zur Geschichte des Liegenschafsrecht im Altertum. (Graz, 1924), pp. 33 ss. Cfr.: Ibid. p. 368 , nota 113 .

${ }^{188}$ LUMBROSO, G., op. cit., 307. Hernias perdió el pleito. Cfr.: PESTMAN, P. W., The archive..., op. cit., p. 165.

${ }^{189}$ Pap. Turin, I, p. 7 1.0-13. Cfr.: Ibid. p. 87. Esta sería una prueba más, en contra del criterio que sostiene Wolf al considerar que no se registraban las herencias. Cfr.: WOLF, H. J., "Registration of Conveyances in Ptolemaic Egypt", en Aegyptes 28 (1948), p. 63. Cita otras evidencias en contra de esta opinión: RAMOS FOLQUÉS, R., "El Registro de la Propiedad egipcio según la literatura papirológica egipcia", en Revista Crítica de Derecho Inmobiliario 38 (1962), p. 373.

${ }^{190}$ Existió un prohibición específica referida a las transcripciones de las ventas, en el sentido de que no podía realizarse la misma si el vendedor no había podido probar que él era el propietario. $C f r .: B G U 1213$; 11. 9-10 y LENGER, M.T., op.cit., p. 247, All.35. Y, del mismo modo que la tasa de la transmisiones por ventas se hizo extensiva después a las herencias, también pudo haber ocurrido lo mismo en el caso de las inscripciones.

${ }^{191}$ WOLFF, H. J., "Control público de la legitimación de disposición en Egipto en la época ptolemaicoromana", en Revista Crítica de Derecho Inmobiliario 348(1962), pp. 289 ss. El autor, tras destacar el origen griego y no egipcio de la publicidad inmobiliaria, centra especialmente su estudio en la época romana. Cfr.: p. 292 ss.

${ }^{192}$ TELL, A., op. cit., p. 185.

${ }^{193}$ RAMOS FOLQUES, R., op. cit., p. 331.

${ }^{194}$ WOLFF, H. J., op. cit., pp. 289 ss.
} 
Se alega como argumento en favor de Hermias que la casa la había recibido en herencia de sus ascendientes, sin puntualizar si la sucesión había sido ab intestato o testamentaria ${ }^{195}$, lo cual podría ser irrelevante desde el punto de vista fiscal, porque eran los sucesores en general los obligados al pago de la tasa y a realizar la inscripción, por cuanto lo que era de interés para el Estado y lo que estaba realmente gravado, era la transmisión de la propiedad.

La tasa que gravaba la herencia habría sido la misma que se imponía a las transmisiones de la propiedad por venta, que progresivamente se fue extendiendo, primero a las hipotecas, y, más tarde, se amplió, a las transmisiones hereditarias. Una vez satisfecho el impuesto se extendía una carta de pago a modo de recibo y su redacción se incluía en la parte derecha del documento objeto de inscripción. Parece que sin el pago de la tasa no se procedía al registro indicado ${ }^{196}$.

Se trataba de una tasa ad valorem ${ }^{197}$; era el enkyklion $^{198}$ que más tarde, en el Egipto romano, se sabe que gravó con un $10 \%$ el valor de las cosas. Y, como aparece en el propio papiro, en relación a los argumentos de la defensa de los choachytes ${ }^{199}$, su falta de pago se sancionaba con una multa ${ }^{200}$ y con la anulación de las gestiones realizadas por la Administración; gestiones que podrían referirse a la redacción del documento de transmisión ${ }^{201}$.

Maspero $^{202}$ ha creído encontrar el fundamento de esta tasa sucesoria, en la propia consideración del rey. Sus argumentos parten del hecho de que, en Egipto, todo le pertenece y, lógicamente, a la muerte de un sujeto todos sus bienes revierten a él, ya que es él el propietario natural de los mismos. El rey, una vez los ha recibido, hace abandono de su derecho, contentándose con quedarse sólo con una parte de la herencia, que es la que se corresponde con el gravamen sucesorio. Este planteamiento justificaría que no se hubiera previsto ningún caso de exención del mismo.

De ser efectivamente éste el fundamento de dicha imposición no podría hacerse extensivo a Roma porque ésta se apoyaba en pilares completamente distintos. La concepción romana del deber de contribuir al gasto público, tenía carácter ocasional porque se basaba en la satisfacción de las necesidades bélicas y constituía una obligación ciudadana de cooperación ${ }^{203}$ nacida de la propia naturaleza de la República y de la vinculación existente entre los ciudadanos; el impuesto regular era contrario a la concepción romana de libera res publica ${ }^{204}$. Este podía considerarse como el fundamento de la imposición directa. Y el aprovechamiento por el erario público de las actuaciones privadas de los ciudadanos en las que tenía algún tipo de participación el Estado romano, era el fundamento de la imposición indirecta ${ }^{205}$. La carencia de un sistema fiscal, tal como se entiende hoy en día, era evidente. Y en este período de continuas guerras civiles, en el

${ }^{195}$ D’ORS, A., Introdución al estudio de los documentos del Egipto romano. (Madrid, 1948), p. 128. ARANGIO RUIZ, V., "Osservazioni sul sistema della successione legittima nel diritto dei papiri”, en Rariora. (Roma, 1946), pp. $131 \mathrm{ss.}$ = Studi economico-giuridico Della R. Università di Cagliari V. (1913). Algunos aspectos sobre la herencia y sobre la sucesión mortis causa, pueden consultarse, además, en: SCHARFF, A., Einführung in die Ägyptische Rechtsgeschichte bis zum ende des Neuen Reiches. I. Juristischer Teil. (Hamburg-New York, 1951), pp. 57 ss. TAUBENSCHLAG, R., The Law of Greco- Roman Egypt in the light of de papyri (332 B.C.- 640 A.D.). (New York, 1944), pp. 15 y 16, pp. 138 ss.

${ }^{196}$ WOLFF, H. J., op. cit., p. 300. RAMOS FOLQUES, R., op. cit., p. 367.

${ }^{197}$ HUSSON, G., - VALBELLE, D., op. cit., p. 299 y 306.

${ }^{198}$ WILCKEN, V., Griechische..., op. cit., pp. 182-185. SCHNEIDER, H., Wirtschaft und Politik. Untersuchungen zur Geschichte der späten römischen Republik. (Earlangen, 1974), pp. 323 ss.

${ }^{199}$ Pap. Tur. 1, p. 7,1.10-13. P. Tor (Mitteis, L., Chrest.31) col. X 1 y ss. P. Par 15 ( UPZ II,161).

${ }^{200}$ Según el propio Pap. Turin I, p.7,1.10-13, la multa por falta de inscripción era de 10.000 dracmas. Cfr.: LUMBROSO, G., op. cit., p. 309.

${ }^{201}$ WOLFF, H. J., op. cit., pp. 300 ss.

${ }^{202}$ MASPERO, H., Les finances de l'Ëgypte sous les Lagides. (Paris, 1905), p. 126.

${ }^{203}$ FERNÁNDEZ DE BUJÁN, A., "Ius Fiscale: Instrumento...", op. cit., p.14 y en especial nota 34.

${ }^{204}$ NICOLET,C., Tributum..., op. cit., p. 62.

${ }^{205}$ NAQUET, H., Des impots indirects chez les romains sous la république et sous l'empire. (París, 1875), pp. 2 ss. 
que en muchos momentos se vivían estados de excepción, la fiscalidad era totalmente arbitraria y se pretendía imponer por la fuerza ${ }^{206}$.

La necesidad de obtener ingresos hizo que primero César, y más tarde los triunviros, se valieran de esta intensa relación con Egipto ${ }^{207}$ para tomar en consideración algunos aspectos de su legislación tributaria.

Por lo que respecta al impuesto sucesorio egipcio, un conocimiento profundo del mismo pudo haber llegado a Roma de la mano de un romano, Rabirio Póstumo ${ }^{208}$, cliente de Cicerón y gran amigo y protegido de César, que ejerció el cargo de ministro de finanzas de Egipto -diocetaen el reinado de Ptolomeo XII Auletés ${ }^{209}$. Este reinado fue legitimado por César, en su primer consulado, con lo que se sentaron las bases del protectorado romano sobre Egipto ${ }^{210}$.

La mala gestión de Póstumo provocó que fuera expulsado de Alejandría y encarcelado junto a sus colaboradores ${ }^{211}$. Logró fugarse y regresó a Roma, sin ningún medio económico y vivió mantenido por la generosidad de César ${ }^{212}$. De este trato tan directo pudo surgir la idea o, cuanto menos, el conocimiento exhaustivo de la tasa sucesoria ptolomaica y pudo haberse forjado la utilidad de su imposición en la Roma del momento ${ }^{213}$. Se obviaron las diferencias existentes entre ambos ordenamientos jurídicos en torno a la concepción de la herencia y de los distintos modos de llamar a la sucesión ${ }^{214}$, y se fijó el punto de mira en el aspecto fiscal. La consideración de la imposición de la tasa hereditaria ha de situarse entre las medidas que se quisieron adoptar para incrementar la capacidad recaudatoria del Estado. Con la misma finalidad se procedió a la actualización del censo y de las tasaciones de los bienes, que ya no se limitaron exclusivamente a los bienes de los ciudadanos de Roma, sino que se ampliaron a los de toda Italia, por haber alcanzado éstos la ciudadanía ${ }^{215}$.

A finales de la República y comienzos del Principado, a diferencia de los períodos precedentes, la institución censal romana desarrollaba diversas finalidades. Hacía las veces de censo de población con finalidades electorales y militares, a la vez que se aprovechaba también con intenciones fiscales ${ }^{216}$.

\footnotetext{
${ }^{206}$ NICOLET, C., Tributum..., op. cit., pp. 87 ss.

${ }^{207}$ CIACERI, E., Processi Politici e Relazioni Internazionali. (Roma, 1918), pp. 1 ss.

${ }^{208}$ LUMBROSO, G., op. cit., p. 308. ORTUÑO PÉREZ, M. E., "El caso del prestamista Rabirio Postumo", en RGDR 23 (2014), pp. 1-19.

${ }^{209}$ LUZZATTO, Appunti di papirologia girudica. (Bologna, 1965), pp. 108 ss. CARCOPINO, J., Julio César. El proceso clásico de la concentración del poder. Trad. esp. $2^{\mathrm{a}}$ ed. (Madrid, 2004), pp. 313 ss.

${ }^{210}$ Dion Casio, 39,2; Cicerón, pro C. Rab. Post. 3,6. Cfr.: CIACERI, E., op. cit., p. 43, en especial nota 4 y p. 199.

${ }^{211}$ Cicerón, pro Rab. Port. 22 y 39.

${ }^{212}$ Ibid. 39. Cfr.: ORTUÑO PÉREZ, M. E., “El caso...”, op. cit., p. 13. WILL, E., Histoire ..., op. cit. Vol. II, pp. 439 ss; en especial p. 443.

${ }^{213}$ Autores de finales del siglo XIX habían considerado ya la posibilidad de que el impuesto sucesorio romano derivó de Egipto. Cfr.: LUMBROSO, G., op. cit., p. 308. WILCKEN, V., Griechsche..., op. cit., p. 183. SCHANZ, "Studien zur Geschichte und theorie der Erbschaftstever", en Finanzarchiv, XVII, 1 (1900), p. 7. Todo ello citado también en: CICOTTI, E., op. cit., p. 111, nota 1.

${ }^{214}$ Sobre el derecho sucesorio egipcio, cfr.: PIRENNE, J., op. cit., vol. III, pp. 301 ss. REVILLOUT, E., Précis de droit égypptien.(París, 1903). Vol. I y II. ARANGIO RUIZ, V., "Osservazioni sul sistema...”, op. cit., pp. 131 ss. ID., La successione testamentaria secondo i papiri greco-egizii. (Napoli, 1906). VOLTERRA, E., Diritto Romano e Diritto orientali (Bologna, 1937), pp. 135 ss., y la bibliografía allí citada. D’ORS, A., Introducción al estudio de los documentos del Egipto romano. (Madrid, 1948), pp. 128 ss.

${ }^{215}$ La operación censoria en estas tierras se llevó a cabo en los municipios. Cfr.: TANFANI, L., Contributo alla storia del Municipio Romano. (Roma, 1970).

${ }^{216}$ CAÑAS NAVARRO, P., “Aspectos jurídico-tributarios del censo romano”, en $R G D R 13$ (2009), pp. 1 ss. NICOLET, C., Rendre à César. Économie et société dans la Rome antique. (París, 1988), pp. 224 ss.
} 
Su función en este ámbito fue muy relevante. A diferencia de Egipto ${ }^{217}$, en este momento no podía considerarse que en Roma existiera un catastro en donde figurara la titularidad de los bienes inmuebles ${ }^{218}$. Partiendo de la professio censualis de los ciudadanos, era en el censo en donde se apoyaba la exacción fiscal ${ }^{219}$, y, a la vez, constituía también el elemento que permitía mantener un equilibrio socio-económico entre los habitantes de la ciudad ${ }^{220}$. Todo ello sin perjuicio del gravamen tributario que pesaba también sobre los no ciudadanos, el cual estaba en función de la ciudad o provincia de la que formaran parte ${ }^{221}$.

A partir del censo se imponía la exacción de los impuestos directos, pero este control censal servía de base también para poder aplicar los impuestos indirectos y, en concreto la tasa que nos ocupa. Cualquier cambio de titularidad en concepto de herencia podría haberse controlado a través de la inscripción en el censo, a la que habría precedido el cumplimiento de las exigencias establecidas para la apertura de la sucesión y la adquisición de la herencia.

Julio César pudo haber utilizado el censo para aplicar la tasa que gravaría las herencias cuya forma y contenido habría tomado de Egipto. Todo apunta a que debió trabajar en ello y que dicho proyecto debió incluirse en el Acta Caesariana ${ }^{222}$, pero su asesinato, el 15 de marzo del año 44 a.C., truncó todos los proyectos.

Legitimados por la figura del dictador y obligados por la necesidad económica ${ }^{223}$, los triunviros se arriesgaron a intentar aplicar la tasa que gravaría las herencias. Para ello promulgaron un edicto que provocó una oposición tan radical que impidió que la tasa llegara a aplicarse. De todo ello nos ha informado Apiano ${ }^{224}$ : “... Se publicó un edicto de que los propietarios de esclavos aportaran por cada uno de ellos la mitad de las veinticinco dracmas fijadas para la guerra de Casio y Bruto, y que aquellos que disfrutaran de alguna propiedad por razón de herencia contribuyeran con una parte proporcional.

El pueblo destrozó este edicto con furia salvaje, pues les llenó de cólera que, después de haber dejado exhausto el tesoro público, de haber esquilmado las provincias y de oprimir a la misma Italia con tributos y tasas y confiscaciones, no para guerras extranjeras ni para extender el imperio, sino contra enemigos personales y en defensa del poder particular de cada uno -por lo cual precisamente habían acontecido las proscripciones, matanzas y esta penosísima hambre, todavía trataran los triunviros de quitarles, incluso, lo que les quedaba.

Se unieron en bandadas gritando, y a los que no se les unían les arrojaban piedras y los amenazaban con saquearles sus hogares y prenderles fuego. Finalmente, el pueblo en su totalidad se sublevó $[\ldots]$ ".

${ }^{217}$ Sobre el catastro ptolomaico, cfr.: DÉLÉAGE, A., "Les cadastres antiques jusqu'à Dioclétien”, en Études de Papyrologie. 1934, pp. 79 ss. TALAMANCA, M., "Catastro (storia)”, en ED VI (1960), p. 480.

${ }^{218}$ Existe constancia del mismo a través de los agrimensores de los siglos I y II d.C., pero no antes. Cfr.: TALAMANCA, M., op. cit., p. 481.

${ }^{219}$ D.50,15,4 pr (Ulp., 3 de cens.). Cfr.: TALAMANCA, M., op. cit., p. 482.

${ }^{220}$ NICOLET, C., op. cit. pp. 196-197.

${ }^{221}$ CAÑAS NAVARRO, P., op. cit., p. 8.

${ }^{222}$ D. 1,2,2,44. (Pomp., Lib. sing. ench.). Cfr.: ORTUÑO PÉREZ, M. E., “Aulo Ofilio: De legibus vicensimae primus conscribit", op. cit., pp. 1-23. Pendiente de publicación. Confirma también este extremo la narración de Dion Casio en su Historia de Roma, que cuando se refiere a Augusto y a la creación del Erario Militar, y a las medidas adoptadas para incrementar la recaudación, indica que se aprobó la vicésima que gravaría las herencias y las donaciones testamentarias. Según el emperador este impuesto lo había encontrado entre los papeles de César. Cfr.: Dion Casio 55,25.

${ }^{223}$ DE MARTINO, F., "Sugli aspetti giruidici del triumvirato", en Diritto, Economia e Società nel mondo romano. Vol. II. Diritto Pubblico. (Napoli, 1966), pp. 515 ss. [= en Scritti in onore di Mario Attilio Levi (Como, 1993), pp. 67 ss.]. HEISCHELHEIM, Historia social y económica de Roma. Intrd. J. M. Blázquez. Trad. esp. (Madrid, 1982), pp. 79 ss.

${ }^{224}$ Apiano, 5,67. Traducción: A. Sancho Royo, Historia Romana III. Biblioteca Clásica Gredos 84 (Madrid 1985) 290291. 
Para la economía de la época, la aplicación de esta tasa tenía una importancia esencial. Pero tuvo que esperar a que Augusto lograra este fin, no sin antes sortear la oposición del Senado que accedió a su aprobación como un mal menor, para evitar que se aplicara un impuesto directo sobre los fundos ${ }^{225}$. Al final, se aprobó la Lex Iulia de Vicesima Hereditatium ${ }^{226}$, pero la República había dejado ya de existir.

\section{CONCLUSIÓN}

En las postrimerías de la República, en tiempos de Julio César, se había llegado al límite de la imposición fiscal, en concreto, de la imposición directa, con la que se pretendía hacer frente, de una manera inmediata, a los ingentes gastos militares, a la vez que se quería corregir la gran inflación existente.

Para afrontar esta situación y para atender a las necesidades indicadas, el dictador se vio abocado a arbitrar una serie de medidas con las que poder incrementar la capacidad recaudatoria del Estado republicano. Y, para ello, recurrió a la imposición indirecta y, en concreto, trató de crear e imponer una tasa que gravaba las herencias.

La idea del impuesto procedía de Egipto, lo que ha dejado en evidencia la afinidad entre aquellos pueblos de la antigüedad. Y su recaudación podría haber resultado altamente rentable porque las diferentes guerras civiles podrían haber incrementado este tipo de tributación.

La intención de César se vio truncada con su asesinato. Pero los triunviros habían ratificado todos sus actos y todos sus planes de futuro ${ }^{227}$, por lo que, ante las necesidades completamente insostenibles por la maltrecha economía romana y ante los inminentes gastos militares que generaría la guerra de Octaviano contra Pompeyo, pudieron tener en cuenta las directrices marcadas por su predecesor e intentaron crear este nuevo gravamen, promulgando un edicto, de cuyo contenido nos da cuenta Apiano, en el que se estableció que los propietarios de los esclavos aportaran la mitad de las veinticinco dracmas fijadas para la guerra de Casio y Bruto y que los que hubieran recibido alguna propiedad en concepto de herencia contribuyeran con una parte proporcional de la misma ${ }^{228}$. La normativa fiscal, en relación a la herencia, había estado precedida de una normativa reguladora de aspectos de derecho sustantivo, especialmente propiciatoria de la eficacia de la sucesión testamentaria. Y el poder político no tuvo inconveniente en transformar el régimen fiscal imperante hasta entonces -basado en la solidaridad ciudadana y en el carácter extraordinario de los tributos- para dejar paso a los impuestos de carácter permanente, entre ellos, la tasa sobre las herencias.

Pero la excesiva presión fiscal, el hastío y los abusos llevaron a los ciudadanos a oponerse contra la disposición tributaria con la fuerza del que no tiene nada que perder, evitando así la aplicación del nuevo gravamen ${ }^{229}$. Las contiendas no cesaron y la situación inflacionaria tampoco.

\footnotetext{
${ }^{225}$ Nicolet entiende que la razón de la oposición popular estaba en que se consideraba un impuesto de subditos y no de ciudadanos. Cfr.: NICOLET, C., The World of the citizen in Republican Rome. (Berckeley, 1980), pp. 184-185.

${ }^{226}$ Dion Casio 56,28 y Plinio el Joven, Panegiricus de Trajano 37-40 ed. de D' ORS,A., Plinio el Joven. Panegírico de Trajano.(Madrid, 1955). CARDARELLI, S., "Tributi successori”, en ED XLV (199,2), p.154. LÓPEZ RENDO, C., "De la vicesima hereditatium al impuesto sucesorio en el derecho español", en Dereito Romano. Poder e Direito. (Lisboa, 2013), pp. 201 ss., entre otros.

${ }^{227}$ Apiano, 3,5. Apiano nos relata que Marco Antonio poseía el Acta Caesariana.

${ }^{228}$ Apiano 5,67.

${ }^{229}$ Ibid.
} 
La necesidad de incrementar los ingresos del Estado perduró también con Augusto. Y éste, amparado en la legitimidad que le ofrecía el Estado romano y apoyándose en el contenido del Acta Caesariana, intentó su aprobación enfrentándose a la oposición del Senado, que supo vencer estratégicamente con la amenaza de la imposición de un impuesto fundario en Italia.

\section{REFERENCIAS}

AA. VV., Historia de Egipto. MANETÓN. Ed. de J. Jiménez Fernández y A. Jiménez Serrano. (Madrid, 2008).

AA. VV., Lineamenti di Storia del Diritto Romano. (Coord. M. Talamanca), $2^{a}$ ed. (Milano, 1989), pp. 355 ss. CIZEK, E., Mentalités et institutions politiques romaines. (s/1, 1990), pp. 147 ss.

ALFÖLDY, G., Der frührömische Reiteradel und seine Ebrenabzeichen. (Roma, 1979), citada también por

, Historia social de Roma. Trad. esp. (Madrid, 1987), pp. 120 ss.

APARICIO PÉREZ, A., “Aportaciones del Derecho romano a la fiscalidad moderna. I.”, en RGDR 12 (2009).

APIANO, 5,67. Traducción: A. Sancho Royo, Historia Romana III. Biblioteca Clásica Gredos 84 (Madrid 1985) 290-291.

ARANGIO RUIZ, V., Historia del Derecho de Roma. $4^{\text {a }}$ ed. Trad. esp. (Madrid 1980).

, “Osservazioni sul sistema della successione legittima nel diritto dei papiri”, en Rariora. (Roma, 1946), pp. 131 ss. = Studi economico-giuridico Della R. Università di Cagliari V. (1913).

BECERRA OLIVA, G., La República romana: organización política, luchas sociales y guerras civiles. (Buenos Aires, 1944)

BETTI, E., La crisi della republica e la genesi del principato in Roma. A cura di G. CRIFÓ (Roma, 1982),

BIONDI, B., Sucesión testamentaria y donación. Trad. esp. (Barcelona, 1960).

BLANCH NOUGUÉS, J. Ma ., "Una visión histórico-jurídica sobre el ejército romano", en RGDR 17 (2011).

, "Reflexiones en torno al interés jurídico del tributo y del derecho fiscal", en Hacia un Derecho Administrativo y Fiscal Romano. (Madrid, 2011), pp. 130 ss.

CAGNAT, M. R., Étude historique sur les impôts indirects chez les romains jusqu'aux invasions des barbares. (Roma, 1966), p. 6.

CALDERINI, A., Dizionario dei nomi geografici e topografici dell'Egitto greco-romano. (Milan, 1966), pp. 385-386.

CAÑAS NAVARRO, P., “Aspectos jurídico-tributarios del censo romano”, en RGDR 13 (2009).

CARCOPINO, J., Julio César. El proceso clásico de la concentración del poder. Trad. esp. $2^{\mathrm{a}}$ ed. (Madrid, 2004). 
CARDARELLI, S., “Tributi successori”, en ED XLV (1992).

CÀSSOLA, F., - LABRUNA, L., Linee di una storia delle istituzioni republicane. $2^{\mathrm{a}}$ ed. (Napoli, 1979).

CERAMI, P., “Il sistema Ofiliano”, en La Codificazione nel Diritto dall'antico al Moderno. (Coord. E. Dovere). (Napoli, 1998), pp. 83 ss.. Sobre la referencia a las vigésimas en la obra de Ofilio, cfr:.

CIACERI, E., Processi Politici e Relazioni Internazionali. (Roma, 1918), pp. 1 ss.

CICERÓN, M. T., Tres discursos jurídicos. Ed. y trad. de J. M. ROYO ARPÓN. (Madrid, 2004).

CORONA BUSTAMANTE, F., Curso completo de Geografía universal antigua y moderna. (París, 1858) y ed. Pontificia Università Laterenense, 1961.

CRIFÒ. G., “Attività normativa del Senato in età repubblicana”, en BIDR 10 (1968), 3ª serie.

D’ORS, A., “Cicerón, sobre el Estado de excepción”, en Ensayos de Teoría Política (Pamplona, 1979).

, Introducción al estudio de los documentos del Egipto romano. (Madrid, 1948).

, Plinio el Joven. Panegírico de Trajano.(Madrid, 1955).

DE MARTINO, F., "Il modello della cità stato", en Diritto, Economia e Società nel mondo romano. Vol. I. Diritto Pubblico. (Napoli, 1996).

, "Motivi economici nelle lotte dei populares", en Diritto. Economia..., op. cit., pp. 299 ss., en especial p. 300.

, "Sugli aspetti giruidici del triumvirato", en Diritto, Economia e Società nel mondo romano. Vol. II. Diritto Pubblico. (Napoli, 1966), pp. 515 ss. [= en Scritti in onore di Mario Attilio Levi (Como, 1993), pp. 67 ss.].

, "Sulla Storia dell'equitatus romano", en Diritto, Economia, op. cit., p. 281, en especial, nota 1 , entre otros.

, Storia della costituzione romana. Vol. IV. Parte prima. (Napoli, 1962).

DÉLÉAGE, A., “Les cadastres antiques jusqu’à Dioclétien”, en Études de Papyrologie. 1934, pp. 79 ss.

DENIAUX, E., Clientèles et povoir à l'èpoque de Cicerón. (Roma, 1993), pp. 287 ss.

DI RENZO, F., La finanza antica. (Milano, 1955).

DOMINGO, R., "La jurisprudencia romana, cuna del Derecho”, en Revista Jurídica. Facultad de Jurisprudencia y Ciencias Sociales y Políticas. Universidad de Santiago de Guayaquil. Ecuador. [Revista Jurídica on line]. 2013, p. 5 y 7.

DUPLÁ ANSUATEGUI, A., Videant Consules. Las medidas de excepción en la crisis de la república romana. (Zaragoza, 1990), pp. 155 ss.

FERNÁNDEZ DE BUJÁN, A., "Ius fiscale: Instrumentos de política financiera”, en Iura 58 (2010). 
, "Perspectivas de estudio en temática de Derecho Administrativo romano surgidas a tenor del pensamiento y de la obra de Giambattista Impallomeni”, en INDEX 26 (1998), pp. 464 ss.

FUENTESECA, P., Historia del Derecho Romano. (Madrid, 1987), p. 235.

, “Ius Publicum y pago de impuestos”, en Direito Romano. Poder e Direito. (Coimbra, 2013), pp. 861-862.

GABBA, E., "Esercito e fiscalità a Roma in età repubblicana", en Armées et fiscalité dans le monde antique. (París, 1976-1977).

\& LAFFI, V., Sociedad política en la Roma republicana (Pisa, 2000), pp. 209 ss.

GARCÍA CAMIÑAS, J., Delator: Una aproximación al estudio del delator en las fuentes romanas. (Santiago de Compostela, 1983).

GIUFFRÈ. V., Aspetti costituzionali del potere dei militari nella tarda "respublica". (Napoli, 1973), 2013), p. 90.

Homines militares e status rei publicae. Torsioni di una constituzione. (Napoli,

GOUKOWSKY, P., El mundo griego y el oriente. T. II. El siglo IV y la época helenística. Trad. esp. (Madrid, 1998), p. 420 y 467.

GUIRAUD, P.,"L'impôt sur le capital sous la Rèpublique romaine”, en NRHDFE 20 (1904). (Reimpr. 1985).

HEILPORN, P., Thèbes et ses taxes.Recherches sur la fiscalité en Égypte romaine. (Ostraca de Strasbourg II ). (Paris, 2009).

HEISCHELHEIM, Historia social y económica de Roma. Intrd. J. M. Blázquez. Trad. esp. (Madrid, 1982).

HINRICHS, F. T., Histoire des Institutions Gromatiques. (París, 1989).

HUMBERT, G., Saggio sulle finanze e sulla contabilità pubblica presso i romani. Trad. Ital. (s/ 1 , reed. 1886)

HUSSON, G., - VALBELLE, D., Instituciones de Egipto. Trad. esp. (Madrid, 1998).

KAMM, A., op. cit., pp. 101 ss. ARBIZU, J. M., op. cit., pp. 307 ss. CERAMI, P., "Cesare dictador e il suo progetto constituzionale: dal consociativismo al potere personale", en AUPA 43 (1995), pp. 427 ss.

KUNKEL, W., Derecho Privado Romano. Trad. esp. (Madrid, 1985).

LAFFI, V., "Poderes triunvirales y órganos republicanos", en Sociedad y política en la Roma republicana. (Siglos III a I a.C.). (Pisa, 2000).

LÊVÊQUE, P., El mundo helenístico. Trad. esp. (Barcelona, 2005).

LÓPEZ RENDO, C., "De la vicesima hereditatium al impuesto sucesorio en el derecho español”, en Dereito Romano. Poder e Direito. (Lisboa, 2013), pp. 201 ss., entre otros.

LURASCHI, G., "Il < praemium> nell'esperienza giuridica romana”, en Studi in onore di Arnaldo Biscardi. Vol. IV. (Milán, 1983).

LUZZATTO, Appunti di papirologia girudica. (Bologna, 1965). 
MASI DORIA, C., Modelli giuridici, prassi di cambio e "medium" linguistico. Un itinerario dell' espansionismo romano. (Napoli, 2012).

, Spretum Imperium. (Napoli, 2000)

MASPERO, H., Les finances de l’Ëgypte sous les Lagides. (Paris, 1905), p. 126.

MITTEIS, L., Grundzüge und Chrestomathic der PapyrusKunde (Teubner, 1912) y (Hildesheim, 1963).

MODRZEJEWSKI, J., "Réflexions sur le droit ptolemaïque”, en IURA 15 (1964), pp. 53 ss.

MOMmSen, T., Compendio del Derecho Público Romano. $1^{\mathrm{a}}$ ed. Argentina (Buenos Aires, 1942), pp. 27 ss.

NAQUET, H., Des impots indirects chez les romains sous la république et sous l'empire. (París, 1875).

NEUMANN, A., voz: "Veterani”, en PW. Supl. 9 (Stuttgar, 1962), pp. 1597 ss.

NICOLET, C., Censeurs et publicains. Économie et fiscalité dans la Rome antique. (s/l, 2000).

, L’Ordre Équestre a l’Époque Républicaine. (312-43 av. J.-C.). T. I. (París, 1974).

, Rendre à César. Économie et Société dans la Rome Antique. (París, 1988).

, The World of the citizen in Republican Rome. (Berckeley, 1980).

1976).

, Tributum. Recerches sur la fiscalité directe sous la republique romaine. (Bonn,

ORTUÑO PEREZ, Ma . E., "A new perspective on the limitation of legacies. (Lex Falcidia de Legatis), en SDHI 80 (2014), pp. 411 ss.

, “Aulo Ofilio: De legibus vicensimae primus conscribit”, pendiente de publicación.

, “El caso del prestamista Rabirio Postumo", en RGDR 23 (2014), pp. 1-19.

,"Una limitación de la capacidad patrimonial de la mujer en el ámbito sucesorio: La Lex

Voconia", en Mulier. Algunas Historias e Instituciones de Derecho Romano. Ed. R. Rodríguez López. Ma J. Bravo Bosch (Madrid, 2014)

PACCHIONI, G., Breve Historia del Imperio Romano. (Madrid, 1944).

PAIS, E., "L'aspirazione di Cesare al trono e l'opposizione tribunicia durante gli anni 45-44 aC", en Aufstieg und Niedergang der Römischen Welt. Von den Anfängen Roms bis zum Ausgang der Republik. Vol. I, (Walter de Gruyter- Berlin-New York, 1973).

PARIBENI, R., L'età di Cesare e di Augusto. (Bologna, 1950).

PEPPE, L., Posizione giuridica e ruolo sociale della donna romana in età repubblicana. (Milano, 1984), pp. 138 ss. Y, en especial, las fuentes y la bibliografía de la nota 178.

PESTMAN, P. W., The archive of the Theban Choachytes (Second Century B.C.). (Leuven, 1993).

PIRENNE, J., Historia del antiguo Egipto. Vol. III. Trad. esp. (Barcelona, 1983).

POLVERINI, L., "L'aspetto sociale del passaggio dalla repubblica al principato", en Aevum 38 (1964); 39 (1965). 
PRÉAUX, C., "La singularité de l'Egypte dans le monde greco-romaine”, en Chron. Egipt. 25 (1950) , L’ Économie royale des Lagides. (Bruselas, 1939).

, “Sur la reception des droits dans L’Egypte greco-romaine”, en RIDA 5 (1950), pp. 352 ss.

RAMOS FOLQUÉS, R., "El Registro de la Propiedad egipcio según la literatura papirológica egipcia”, en Revista Crítica de Derecho Inmobiliario 38 (1962).

REVILlOUT, E., Précis de droit égypptien. (París, 1903). Vol. I y II.

ROLDÁN, J. M., Historia de Roma. T. I. La República Romana. 5a ed. (Madrid, 1999), pp. 625 ss.

ROSTOVTZEFF, Historia social y económica del mundo helenístico. Vol.I, Trad. esp. (Madrid, 1967).

ROTONDI, G., Leges publicae populi romani. (Hildesheim- Zürich - New York, 1990) , "Osservazioni sulla legislazione comiziale romana di diritto privato", en Scritti. Vol I. (Milano, 1910), pp. 4 ss.

SÁINZ DE BUJANDA, F., Ordenamiento financiero de la antigua Grecia y el período helenístico. (Madrid, 2013).

SCHANZ, "Studien zur Geschichte und theorie der Erbschaftstever", en Finanzarchiv, XVII, 1 (1900).

SCHARFF, A., Einführung in die Ägyptische Rechtsgeschichte bis zum ende des Neuen Reiches. I. Juristischer Teil. (Hamburg-New York, 1951), pp. 57 ss. TAUBENSCHLAG, R., The Law of Greco- Roman Egypt in the light of de papyri (332 B.C.- 640 A.D.). (New York, 1944), pp. 15 y 16, pp. 138 ss.

SCHNEIDER, H., Wirtschaft und Politik. Untersuchungen zur Geschichte der späten römischen Republik. (Earlangen, 1974).

SCHULZ, Derecho Romano Clásico. Trad. esp. (Barcelona, 1960), pp. 198 ss. KASER, M., Das Römische Privatrecht. Erster Abschnitt. (München, 1975), pp. 320 ss. JÖRS, P., , Principios del Derecho Romano. (Madrid, 1990).

SHIPLEY, G., El mundo griego después de Alejandro (323-30 a.C.). Trad. esp. (Barcelona, 2001).

SPAGNUOLO VIGORITA, T.- MERCOGLIANO, F., voz: "Tributi (dir. rom.)", en ED 45 (1992).

TALAMANCA, M., “Catastro (storia)”, en ED VI (1960), p. 480.

, Istituzioni di Diritto Romano (Milano, 1990).

, Lineamenti di Storia del Diritto Romano. (Milano, 1989).

TELL, G. A., "El registro de la propiedad en Egipto en la época romana", en Revista Crítica de Derecho Inmobiliario 602 (1991), p. 181. Artículo basado en la obra de: EGER, O., Zum Ágyptischen Grund buchwesen in römischer Zeit. (Leipzig- Berlin, 1909).

TONDO, S., Profilo di storia costituzionale romana. (Milano, 2010), p. 214. 
TORRENT, A., “Inflación y proceso en la legislación municipal”, en RIDA 29 (1972)

, La constitutio antoniniana. Reflexiones sobre el Papiro Giessen 40 I. (Madrid, 2012), pp. 33 ss.

, voz: Lex Iulia de Civitate Latinis et Sociis Danda, en Diccionario de Derecho Romano. (Madrid, 2005).

VOLTERRA, E., Diritto Romano e Diritto orientali. (Bologna, 1937).

WILCKEN, U., Griechische Ostraka. Vol. I. (Amsterdam, 1970), p. 199.

WILL, E., Histoire..., op. cit.Vol. II, pp. 439 ss.

WOLF, H. J., "Control público de la legitimación de disposición en Egipto en la época ptolemaicoromana”, en Revista Crítica de Derecho Inmobiliario 348(1962). , "Plurality of Laws in Ptolemaie Egypt", en RIDA 7 (1960). , "Registration of Conveyances in Ptolemaic Egypt", en Aegyptes 28 (1948).

, "The origin of judicial litigation Among the greeks", en Traditio. Studies in ancient and medieval history, thought and religion. Vol. IV. (New York,1946).

WORP, K.A. - DIJKSTRA, J. H. F., "The administrative position of Omboi and Syene in Late Antiquity”, en Zeitscnift für Papyrologie und Epigrafik (Bonn, 2006), Vol. 155, pp. 183-187.

Recebido em: 26 out. 2017.

Aceito em: 30 nov. 2017. 